\title{
REMOTE SENSING ASSESSMENT OF GLACIAL LOSS AND VEGETATION CHANGE FROM 1989 TO 2016: POND INLET, NUNAVUT
}

By

Ruby R. Pennell

Hons. BSc, University of Toronto, Scarborough, Ontario, 2016

\author{
A major research paper \\ presented to Ryerson University \\ in partial fulfilment of the \\ requirements for the degree of \\ Master of Spatial Analysis (MSA) \\ in the program of Spatial Analysis
}

Toronto, Ontario, Canada

(C) Ruby R. Pennell 2017 


\section{Author's Declaration}

I hereby declare that I am the sole author of this MRP. This is a true copy of the MRP, including any required final revisions.

I authorize Ryerson University to lend this MRP to other institutions or individuals for the purpose of scholarly research.

I further authorize Ryerson University to reproduce this MRP by photocopying or by other means, in total or in part, at the request of other institutions or individuals for the purpose of scholarly research.

I understand that my MRP may be made electronically available to the public. 
Remote sensing assessment of glacial loss and vegetation change from 1989 to 2016: Pond Inlet, Nunavut Ruby R. Pennell, MSA, Spatial Analysis, Ryerson University, 2017

\begin{abstract}
The climate change phenomenon occurring across the globe is having an increasingly alarming effect on Canada's Arctic. Warming temperatures can have wide spanning impacts ranging from more rain and storm events, to increasing runoff, thawing permafrost, sea ice decline, melting glaciers, ecosystem disruption, and more. The purpose of this MRP was to assess the climate-induced landscape changes, including glacial loss and vegetation change, in Pond Inlet, Nunavut. A time series analysis was performed using the intervals 1989-1997, 1997-2005, and 2005-2016. The two methods for monitoring change were 1) the Normalized Difference Snow Index (NDSI) to detect glacial change, and 2) the Normalized Difference Vegetation Index (NDVI) to detect vegetation change, both utilizing threshold and masking techniques to increase accuracy.

It was found that the percent of glacial loss and vegetation change in Pond Inlet had consistently increased throughout each time period. The area of glacial loss grew through each period to a maximum of $376 \mathrm{~km}^{2}$ of glacial loss in the last decade. Similarly, the area of the Arctic tundra that experienced vegetation change increased in each time period to a maximum of $660 \mathrm{~km}^{2}$ in the last decade. This vegetation change was characterized by overall increasing values of NDVI, revealing that many sections of the Arctic tundra in Pond Inlet were increasing in biomass. However, case study analysis revealed pixel clustering around the lower vegetation class thresholds used to classify change, indicating that shifts between these vegetation classes were likely exaggerated. Shifts between the higher vegetation classes were significant, and were what contributed to the most change in the last decade.

The observations of higher glacial melt and increases in biomass are occurring in parallel with the increasing temperatures in Pond Inlet. Relevant literature in the Arctic agrees with the findings of this MRP that there are significant trends of glacial loss and vegetation greening and many studies attribute this directly to climate warming. The results of this study provide the necessary background with regards to landscape changes which could be used in future field studies investigating the climate induced changes in Pond Inlet. This study also demonstrates that significant landscape modifications have occurred in the recent decades and there is a strong need for continued research and monitoring of climate induced changes.
\end{abstract}




\section{Table of Contents}

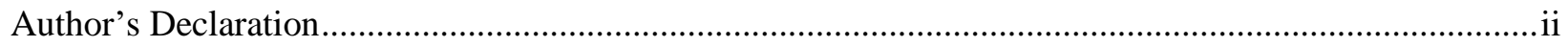

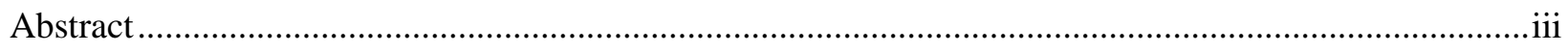

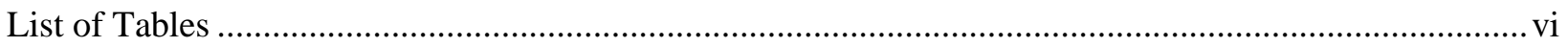

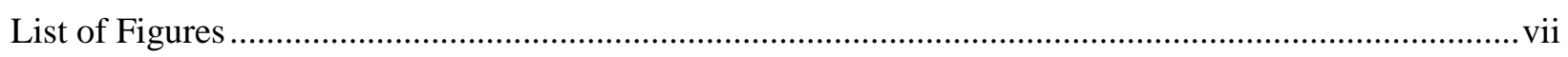

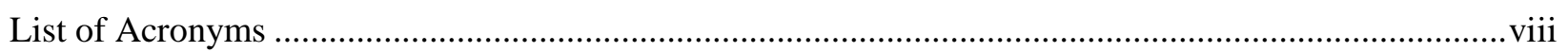

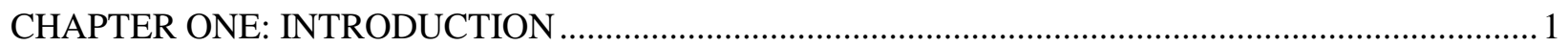

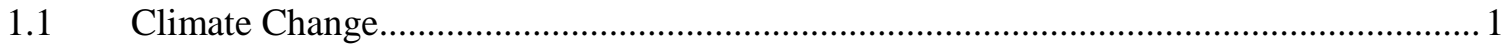

$1.2 \quad$ Image Analysis of Arctic Environments ....................................................................

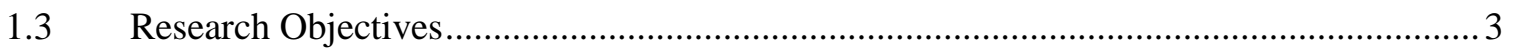

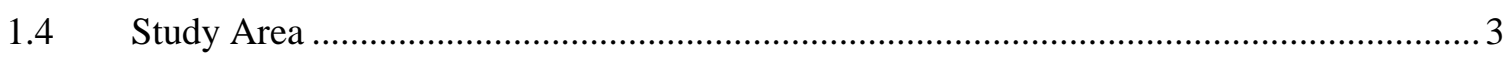

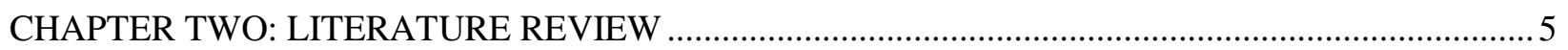

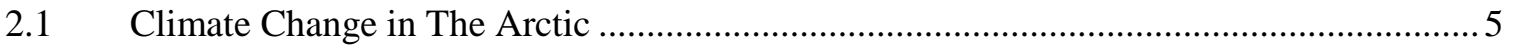

2.1.1 Changing Temperature and Precipitation Patterns.................................................5

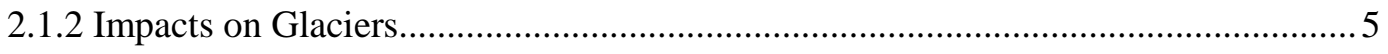

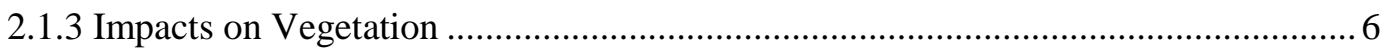

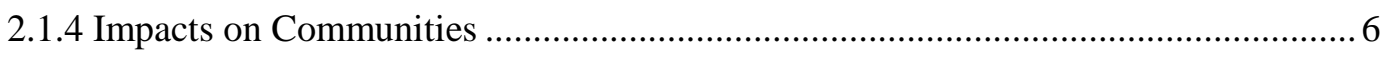

2.2 Change Detection of Snow and Ice Using Remote Sensing ............................................ 7

2.3 Change Detection of Vegetation using Remote Sensing ................................................ 8

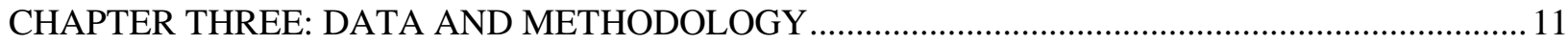

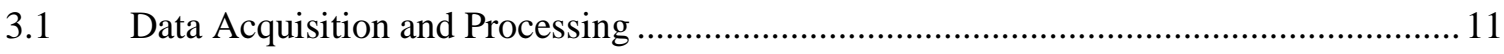

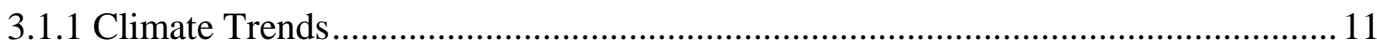

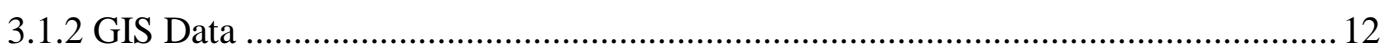

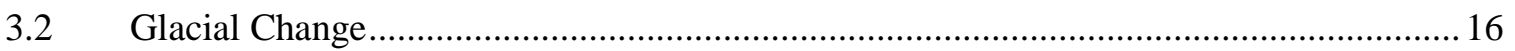

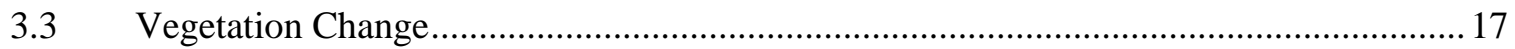

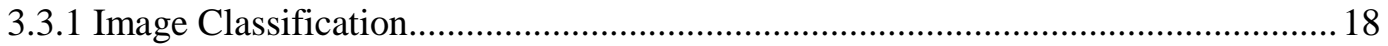

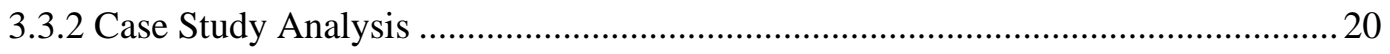

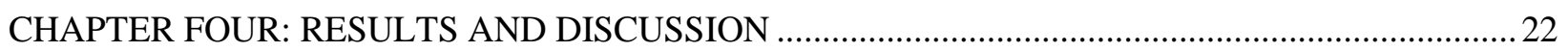

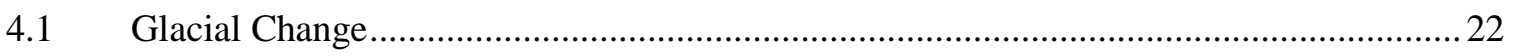

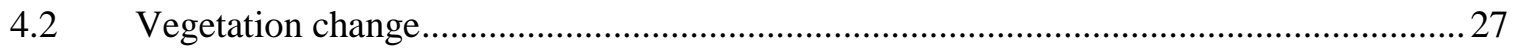

4.2.1 Global Vegetation Change for 1989 to 1997 .......................................................... 32

4.2.2 Global Vegetation Change for 1997 to 2005 ......................................................... 33

4.2.3 Global Vegetation Change for 2005 to 2016 ........................................................ 33

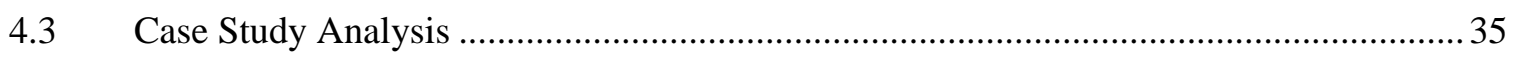

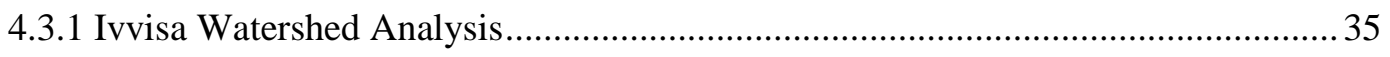

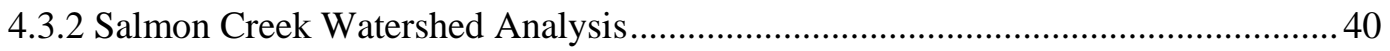


4.3.3 New Water Lake Watershed Analysis 45

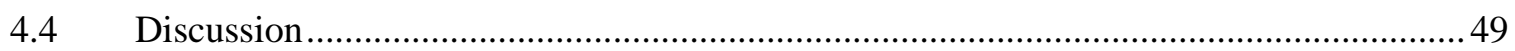

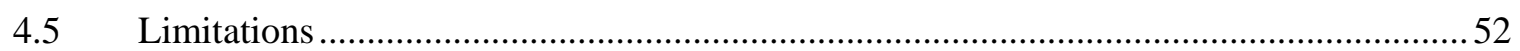

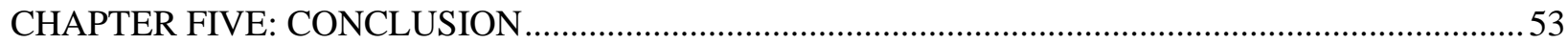

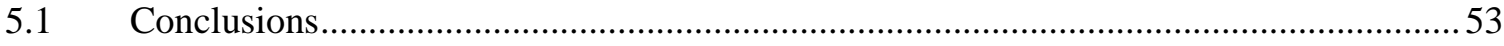

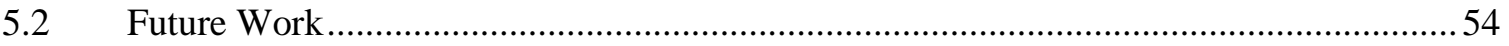

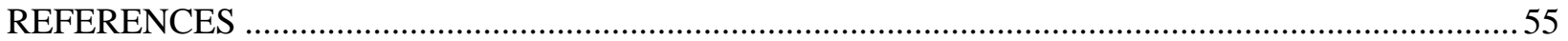




\section{List of Tables}

Table 3.1: Landsat image attributes downloaded from USGS Earth Explorer (USGS, 2017) ................. 13

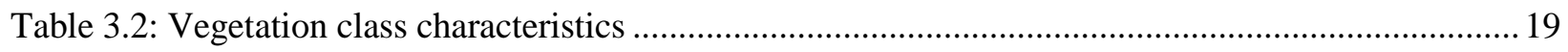

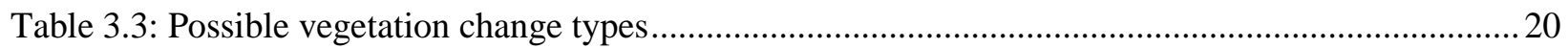

Table 4.1: Accuracy assessment and Kappa statistics for the supervised land cover classification...........22

Table 4.2: Results of marginal glacial loss from NDSI change detection ............................................23

Table 4.3: Global class distribution of NDVI groupings per year ......................................................22

Table 4.4: Global NDVI class changes depicted in the difference image from 1989 to $1997 \ldots \ldots \ldots \ldots \ldots \ldots . . . . .31$

Table 4.5: Global NDVI class changes depicted in the difference image from 1997 to $2005 \ldots \ldots \ldots \ldots \ldots \ldots \ldots . . . . . .31$

Table 4.6: Global NDVI class changes depicted in the difference image from 2005 to $2016 \ldots \ldots \ldots \ldots \ldots \ldots . . . . .31$

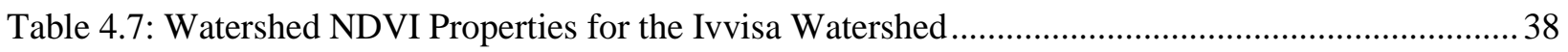

Table 4.8: Pixel change distribution for the Ivvisa Watershed .............................................................. 38

Table 4.9: Watershed NDVI properties for the Salmon Creek Watershed .............................................. 43

Table 4.10: Pixel Change distribution within classes for the Salmon Creek Watershed .......................... 43

Table 4.11: Watershed level NDSI Properties for the New Water Lake Watershed ...............................4 47

Table 4.12: Pixel Change distribution within classes for the New Water Lake Watershed....................... 47 


\section{List of Figures}

Figure 1.1: 1976 to 2016 summer climate trends in Pond Inlet, Nunavut ..............................................2

Figure 1.2: The study area of Pond Inlet, Nunavut ........................................................................

Figure 3.1: The processed image stack $(1: 600,000)$ for Pond Inlet, Nunavut......................................... 15

Figure 3.2: Study area of Pond Inlet with the watersheds used in a case study analysis ........................2 21

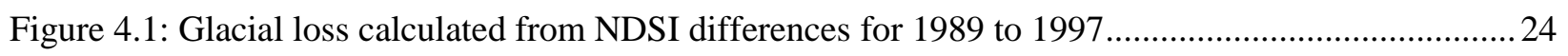

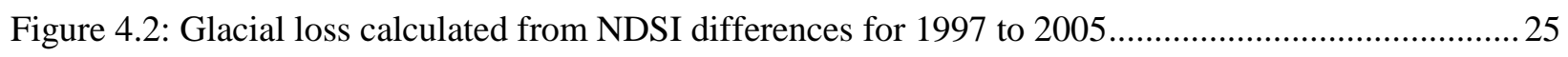

Figure 4.3: Glacial loss calculated from NDSI differences for 2005 to 2016 ........................................26

Figure 4.4: Vegetation change calculated from differencing NDVI classes for 1989 to 1997 .................28

Figure 4.5: Vegetation change calculated from differencing NDVI classes for 1997 to 2005 .................29

Figure 4.6: Vegetation change calculated from differencing NDVI classes for 2005 to 2016 ................... 30

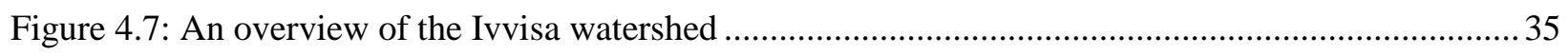

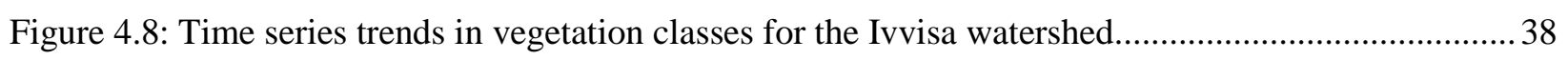

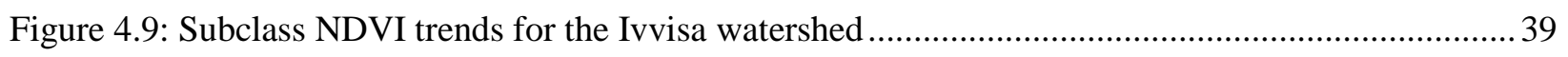

Figure 4.10: An overview of the Salmon Creek watershed ............................................................... 40

Figure 4.11: Time series trends in vegetation classes for the Salmon Creek watershed...........................43

Figure 4.12: Subclass NDVI trends for the Salmon Creek Watershed. ................................................ 44

Figure 4.13: An overview of the New Water Lake watershed...........................................................45

Figure 4.14: Time series trends in vegetation classes for the New Water Lake watershed ...................... 47

Figure 4.15: Subclass NDVI trends for the New Water Lake Watershed.............................................. 48

Figure 4.16: Summer climate trends for Pond Inlet, Nunavut .........................................................50

Figure 5.1: Combined vegetation and glacial change in Pond Inlet, Nunavut..........................................53 


\section{List of Acronyms}

DEM: Digital Elevation Model

DN: Digital Number

GIS: Geographic Information System

ISODATA: Iterative Self-Organizing Data Analysis Technique

L1 T/G: Level 1 systematic and terrain corrected data product

MS: Multispectral

NDSI: Normalized Difference Snow Index

NDVI: Normalized Difference Vegetation Index

NIR: Near Infrared

OLI/TIRS: Operational Land Imager/ Thermal Infrared Sensor

RS: Remote Sensing

SD: Standard Deviation

TM: Thematic Mapper

VNIR: Visible and the Near Infrared 


\section{CHAPTER ONE: INTRODUCTION}

\subsection{Climate Change}

In the last few decades, rising temperatures in Canada's Arctic have been a topic of much discussion. Concerns over the increasing temperatures are well founded, as records indicate that since 1980 the Arctic warming trends have doubled that of the rest of the world (AMAP, 2011). The increases in both land and sea surface temperatures have resulted in the retreat and thinning of sea-ice, a decrease in glacier extent, shortened lake-ice seasons, heavier and more frequent precipitation events, the thawing of permafrost, ecosystem modification, and more (Heartmann et al., 2013; Houghton et al., 2001; Jacques \& Sauchyn, 2009). In addition, positive ice-albedo feedback loops have been established which create an increase in vegetation from diminished snow and ice cover, and permafrost thaw which releases greenhouse gasses, further exacerbating warming trends (Høgda et al., 2013; Houghton et al., 2001). This MRP focuses on two specific climate induced impacts, including changes in glacial extent and changes to plant communities.

Rising temperatures have resulted in a glacial surface warming of 0.8 to $2.2^{\circ} \mathrm{C}$ in the Arctic over the last decade (Sharp et al., 2011). This warming has increased glacial melt rates, which are currently at the highest point they have been in several millennia (Way, 2014). Pan-Arctic greening trends reveal ecosystems are increasing in plant matter (biomass) as higher temperatures allow more growth (Jia et al., 2003). Temperature increases have also led to many ecological changes, such as a longer growing season, shrub expansion into the Arctic tundra, and wetland formation and loss (Burkett \& Kusler, 2000; Epstein et al., 2012; Høye et al., 2007). Furthermore, changes have been noted in community plant and animal structures, affecting an ecosystem's ecological function - such as the ability to act as a carbon sink (Burkett \& Kusler, 2000). The glacial and vegetation changes occurring in Canada's Arctic are the inevitable repercussions of climate change.

Pan-Arctic climate trends are also concurrent with those in Pond Inlet, Nunavut, where average summer maximum temperatures have been increasing for decades (Figure 1.1). There has been nearly a $3.5^{\circ} \mathrm{C}$ increase in average summer temperature from 1976 to 2016. Therefore, it is likely that the significant modifications occurring to glaciers and vegetation communities across the Arctic can also be observed in

Pond Inlet. This MRP is an original contribution to the unique region of Pond Inlet, which utilizes current methods of remote sensing analysis to determine environmental change. 


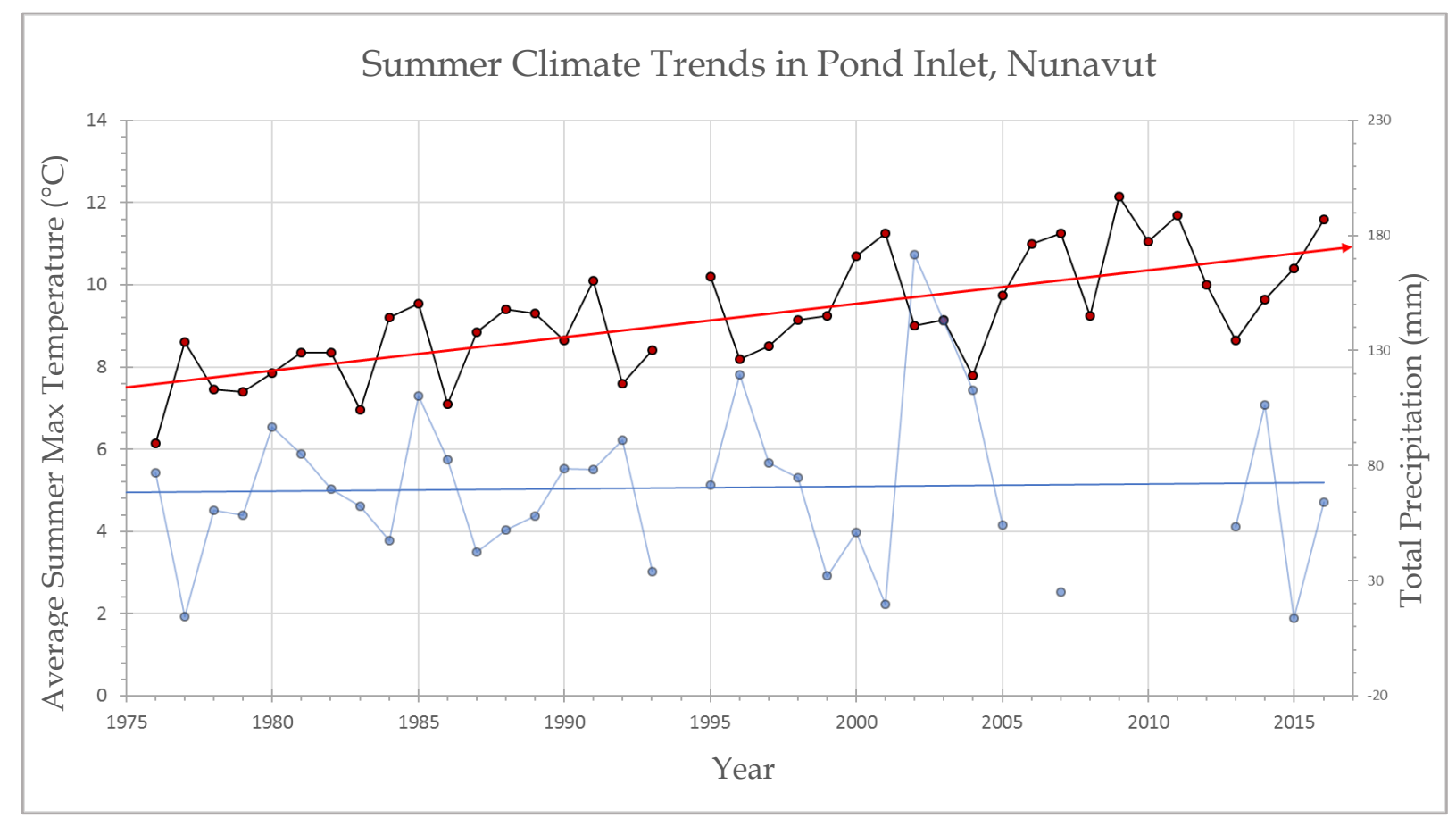

Figure 1.1: 1976 to 2016 average maximum summer (July - August) temperature $\left({ }^{\circ} \mathrm{C}\right)$ in red, and total annual precipitation in blue for Pond Inlet, Nunavut. Climate data recorded at the Environment Canada weather station at Pond Inlet Airport (GOC, 2016).

\subsection{Image Analysis of Arctic Environments}

The scientific use of remote sensing (RS) techniques has flourished since the public dissemination of remotely sensed images and Geographic Information System (GIS) software. Remotely sensed images are a recording of the energy that is being reflected or emitted from the surface of the earth by a satellite in orbit. These images can be used to monitor land cover changes, including glacial melt and vegetation change. This is an especially useful technique for remote locations where physical access is not possible, or the study area is too large for other monitoring methods. Many studies employ the power of remote change detection to identify climate induced patterns of environmental change (Fraser et al., 2008; Piwowar \& LeDrew, 1995; Selkowitz \& Forster, 2015). Specifically, analysis using multiple images to capture longterm trends is beneficial in Arctic environments where change can be gradual, especially when compared to highly ecologically productive regions like the tropics (Fraser et al., 2008). Since the study area of Pond Inlet, Nunavut is both expansive and moderately inaccessible, satellite derived vegetation metrics trump the conventional approach of field observations for this research. 


\subsection{Research Objectives}

The overall goal of this research is to quantify changes in glacial loss and vegetation characteristics over the last quarter century in the region of Pond Inlet, Nunavut. The time period $(1989-2016)$ was chosen based on what suitable satellite imagery was available from USGS Earth Explorer at the time of download (April 2017). Pond Inlet is located on one of the northern lobes of Baffin Island, just above the Arctic Circle (Figure 1.2). It is well glaciated, with large ice caps pouring down into numerous fjords and has a large expanse of open Arctic tundra. Increasing temperatures can drive changes in Arctic landscapes, this MRP will determine if the Pan-Arctic trends have manifested themselves at the local level (Pond Inlet), and to what extent. To investigate this, this project directly addresses two major research questions;

1) What is the areal extent of glacial loss from 1989 to 2016 ?

2) What are the vegetation changes that have occurred from 1989 to 2016 ?

Firstly, it is hypothesized that increasing temperatures are resulting in accelerated glacial melt in Pond Inlet. Secondly, it is hypothesized that temperature increases have allowed for more vegetation growth, creating shifts towards higher biomass environments. These hypotheses come as logical inferences due to the vast collection of climate change work which suggests these phenomena are true across most of the Arctic.

The deliverables will be both illustrated and quantified using GIS and statistics. Although the net environmental change could be determined solely from the initial and final images of the time series, the two time periods in between (1997 and 2005) will provide further understanding of the trajectory of change and highlight the sub-decadal trends.

\subsection{Study Area}

The study area is one of the northern lobes of Baffin Island, Nunavut; including the town of Pond Inlet, and a large area of ice caps and Arctic tundra valleys (hereafter collectively referred to as Pond Inlet). In total the study area covers just over $6000 \mathrm{~km}^{2}$ (see Figure 1.2). The lobe is split into approximately one third tundra, and two thirds glacier cover. Located in the Arctic Cordillera ecozone, just north of the $70^{\text {th }}$ parallel, vegetation is mostly a mix of tundra plant communities (graminoids, sedges, and prostrate shrubs) on mesic soils, wetlands, or exposed rock (Olthof et al., 2015; Walker et al., 2005). The glacier portion of the site is a grouping of broad interfjord glaciers, ice caps, and perennial snow packs (hereafter collectively referred to as glaciers) which flow down numerous outlet valleys into the Arctic Ocean, and the adjacent lands. 
This area of the low-eastern Arctic is relatively understudied in comparison to the plethora of research available on the high Arctic, and that specific to sea ice change (Way, 2014). One reason for choosing this study location is that in this Arctic range, snowcaps last all year long, yet they are not continuous in extent so that ice cap change can be measured at their borders. The multiple valley outlet glaciers will be particularly useful to visually contrast the changes. In addition, field studies can be set up in this community to allow for future monitoring (Atkinson, pers comm.).

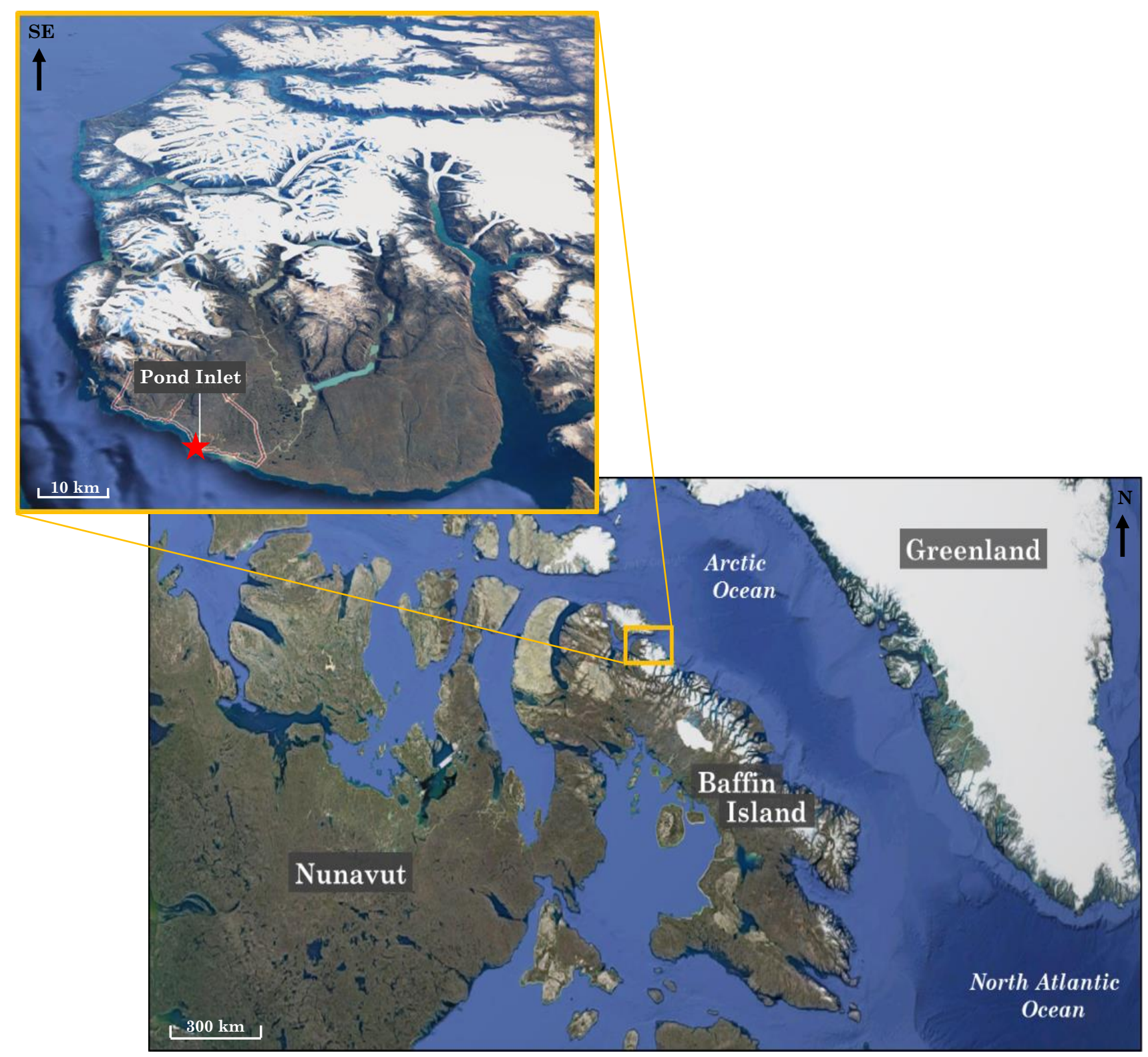

Figure 1.2: The study site located on northern Baffin Island, Nunavut and a view of the glaciated lobe looking southeast over the community of Pond Inlet (Source: Google Maps Imagery, 2017) 


\section{CHAPTER TWO: LITERATURE REVIEW}

The purpose of the literature review is to first build a background on topics relating to this MRP, as well as assess the current state of research relevant to Pond Inlet regarding Arctic climate change and remote sensing techniques for measuring glacial loss and vegetation change. There is particular emphasis on the methods which will be employed, as well as the links between remotely sensed findings and field verified data, which acts to promote the potential for future field work. Since the full implications of climate warming are unknown, and will likely remain so for decades, the monitoring of current and historical environmental conditions is imperative.

\subsection{Climate Change in The Arctic}

\subsubsection{Changing Temperature and Precipitation Patterns}

As previously noted, records show a significant trend of increasing temperatures across the entire Arctic (Jia \& Epstein, 2003; Sharp et al., 2011). Over the last century, temperatures in the Arctic have increased $3.5^{\circ} \mathrm{C}$. There was an intensifying trend after 1980, where Arctic warming rates doubled that of the rest of the globe (Overland et al., 2016). Even conservative model predictions estimate that the current warming trajectory will result in additional temperature increase of $3^{\circ} \mathrm{C}$ to $6^{\circ} \mathrm{C}$ in just 60 years (AMAP, 2011). The collection of research around Nunavut report that climate warming is leading to measurable permafrost degradation (Perreault et al., 2017), wetland and ecosystem disruption (Woo \& Young, 2006), decreased summer snowfall (Screen \& Simmonds, 2012), ice shelf breakup (Vincent et al., 2011), increases in biomass (Olthof et al., 2008), and glacial mass loss (Gardner et al., 2012).

\subsubsection{Impacts on Glaciers}

Many glaciers are known to be shrinking as their mass balance is upset by climate change which is reducing winter snowfall and increasing summer melt (AMAP, 2011; Way, 2014). In a recent study on the Queen Elizabeth Islands, an area just north of Pond Inlet, the mean rate of summer glacier loss in the last half decade was 5 to 7 times greater than the late $20^{\text {th }}$ century average (Sharp et al., 2011). Interannual ice formation is largely impacted by summer melt regimes, and with temperatures continuing to rise, typical summer melt is being exacerbated (Sharp et al., 2011). Studies on glacial loss due to climate change are all in general agreement that there is a significant trend of increasing mass loss, however rates of increase vary depending on location and study period. 


\subsubsection{Impacts on Vegetation}

The increase in summer temperatures has also been known to lead to climate-induced ecosystem 'greening' (Høye et al., 2007; Jia \& Epstein, 2003). Arctic vegetation growth is known to be limited by both temperature and moisture dependencies (Bhatt et al., 2010; Høgda et al., 2013; Vincent et al., 2011). Climate change is reducing these dependencies as warming trends have led to shifts in vegetation phenology and decreased snow in the Arctic tundra, increasing wetness and promoting vegetation growth (Høye et al., 2007; Raynolds \& Walker, 2016). Thawing permafrost can also lead to the release of moisture frozen in soils, creating new wetlands (AMAP, 2011). Some studies however, reveal that climate change is leading to reduced wetness, such as in a study by Perreault et al. (2017), where there has been significant wetland loss from thermo-erosion gullying which induced drainage. A similar study by Woo and Young (2006), revealed that the climate induced reduction of perennial snowpacks was leading to the loss of hydrological inputs into wetland systems. The disparities between studies are due to the heterogeneity of snowpack size. In contrast to these much smaller ice bodies, glaciers can hold a significantly higher volume of water, therefore the supply of a glacier's melt effects last for decades longer.

Altogether, studies reporting on both glacial and vegetation changes occurring in response to climate warming are in agreement with one another. There have been pan-Arctic trends of increasing glacial loss as well as increasing vegetation growth. However, local topography and microclimate variability can influence the effects of global warming, making each study vary in the degree of change experienced (eg. Way, 2014). For instance, Sharp et al. (2011) measured glacial loss in the Queen Elizabeth Islands and found varying rates of mass loss for each glacier, likely due to different climatic regimes uniquely controlling temperature and precipitation in each location. Likewise, Arctic vegetation change is highly heterogeneous and defined by local hydrological and climatic influences (Stow et al., 2004; Van Wychen et al., 2016). Small local changes in relief such as from the rise of a hummock can alter vegetation (Laidler et al., 2008). Therefore pan-Arctic trends remain valid in the large scale, but local studies can show deviation. Although this MRP is not undertaking any novel methodology by using remote sensing to determine climate-induced changes, it will be exploring new findings for the area of Pond Inlet, Nunavut.

\subsubsection{Impacts on Communities}

An additional factor to consider when judging the effects of Arctic climate change is the impact on northern communities. A community infrastructure report by the Government of Nunavut states that Pond Inlet collects its drinking water from a glacier sourced watershed (Aarluk Consulting Inc., 2011). Very few comprehensive studies exist that investigate the adaptations and social-ecological resilience that northern 
communities must have in order to cope with the increasingly changing landscape around them. However, Berkes and Jolly (2001) attempted to determine these adaptations. They concluded that climate change is altering traditional food gathering techniques for northern communities (Berkes \& Jolly, 2001). This impact could extend to water collection for the community of Pond Inlet, where drinking water is gathered from a meltwater fed pond. Research by Loseto et al. (2004), revealed that snowmelt water can be a significant source of methylmercury, which is a toxic bioaccumulater in human and animals. Similarly, research conducted on ice caps just north of Pond Inlet reveal that dangerous brominated flame retardants are stored in Arctic snow (Meyer et al., 2012), and will become increasingly more mobile with elevated melt rates. A comprehensive study of direct and indirect effects of climate change by Downing and Cuerrier (2011) summarize that climate change has serious impacts to both the environment and to communities in the North, which require further scientific research.

\subsection{Change Detection of Snow and Ice Using Remote Sensing}

Change detection using remote sensing methods is a very common and important practice in glaciated environments. Many of the sources above utilize the approach of applying remote sensing to Arctic environments to determine change. Specifically, remote sensing is the predominant methodology for detecting glacial change where other forms of research are impossible or impractical due to study area size and accessibility (Dozier, 1989; Selkowitz \& Forster, 2015). The earliest study using remote sensing products for glacial surveys was in the late 1970's; it documented the new use of satellite research for snow and ice monitoring and inventory (Meyer M.F., 1980). There are now many methods for monitoring glaciers using remote sensing. Typically, monitoring methods involve assessing the amount of glacial loss that is occurring, either through changes in glacier boundary, or tracking of the equilibrium line (boundary between accumulation and wasting zones of a glacier), or glacial mass approximations that account for volume changes by using elevation data (Rabatel et al., 2005; Selkowitz \& Forster, 2015).

Traditionally, many glacial studies utilize the end of summer season (i.e. end of the snow melt period in the Arctic) when melt is at its maximum and fresh early-autumn snow has not yet fallen (Gardner et al., 2012; Rabatel et al., 2005). Paul et al. (2004), outline the issues with mapping glaciers in late season, when debris covers the ice, resulting in poor classification as the spectral signatures between terrestrial features and debris covered ice are too similar. Typically, glaciers are classified based on the signatures of their visible and middle infrared bands (Selkowitz \& Forster, 2015), as snow and ice are highly reflective in the visible spectrum, but highly absorptive in the short-wave infrared spectrum (Dozier, 1989). These properties are utilized in the Normalized Difference Snow Index (NDSI), introduced by Dozier in 1989, which identifies 
the spectral signatures of snow and ice from bare land. Man et al. (2014), compare three main types of remotely sensed glacier mapping which are; visual interpretation through manual digitizing, using the NDSI, and channel differencing of TM 4 and TM 5. The NDSI method is reported to be limited by the differentiating of true glaciers (persistent interannual ice mass) from perennial snow cover patches (Man et al., 2014). This shortfall of the NDSI method is echoed in other studies as well, such as in Selkowitz and Forster (2015) where there is a general trend of NDSI overestimating glacial change (due to the inclusion of snow). However, it is not mentioned that this limitation can be used as an advantage for studies that intend on estimating the total area of ice and snow. Of course no method is quite as accurate as ground truthed monitoring, although skilled image analysts can determine the difference based on visual interpretation. Although, the method of glacial extent identification by visual interpretation or on-screen digitizing is both subjective and time consuming.

The results of the Man et al. (2014) study further show that combining image analysis with climate trends can assist with validating the results of glacial change. Many studies show this use of ancillary data to support their findings (Gardner et al., 2012; Sharp et al., 2011; Vincent et al., 2011). One relevant example of this is from Sharp et al. (2011), who utilized land surface temperature to validate the decrease in glacial mass in the Queen Elizabeth Islands. Although supporting ancillary data like climatic trends can help validate the results of glacial classification and change detection, there are still other issues limiting accuracy which can not be easily resolved. Such issues include errors from cloud contamination (inclusion in the glacial class), as well as fractional errors from resolution (if snow covers less than $50 \%$ of the pixel) (Dietz et al., 2012). Many studies address these issues with the use of threshold values, as it is commonly accepted that NDSI values below 0.4 do not correspond to glacial mass (Burns \& Nolin, 2014; Hall et al., 1998; Selkowitz \& Forster, 2015; Silapaswan et al., 2001).

\subsection{Change Detection of Vegetation using Remote Sensing}

Similar to glacial studies, the use of remote sensing to detect vegetation types is a well practiced method, especially for a multi-temporal analysis (Allen et al., 2012; Jones, 2015; Laidler et al., 2008). Remote sensing to monitor land cover change in response to climate warming can be done through a time series analysis of vegetation to determine the degree of ecological resilience (Cui et al., 2013). Vegetation in the Arctic is commonly characterized using the Normalized Difference Vegetation Index (NDVI), with numerous studies showing considerable success (Jia \& Epstein, 2003; Ozesmi \& Bauer, 2002; Raynolds \& Walker, 2016). The NDVI ratio compares the near infrared bands which are reflected by plants, and the visible red band which is absorbed by plants. On Baffin Island, Laidler et al. (2008) confirmed the success 
of satellite derived NDVI values to quantify vegetation cover through the correlation of ground truthed values. Huete et al. (2002), show that NDVI is a suitable index to quantify the extent, health, and type of vegetation by isolating chlorophyll variations. The range of NDVI values produced is from -1 for the absence of vegetation, to +1 in the case of plentiful vegetation. Although NDVI is a widely used measure in remote sensing, limitations can arise due to sensor, ground, atmospheric, and orbital differences (Lumbierres et al., 2017; Pettorelli et al., 2005). In particular, studies typically show a saturation of NDVI values with false-highs, as well as a strong sensitivity to changes that can occur between solar zenith and azimuth angles (Lumbierres et al., 2017; Pettorelli et al., 2005). Yet, there are some discrepancies between authors on this matter, such as Stow et al. (2004), who report NDVI to be less sensitive to variations in lighting and soil moisture conditions. One method to reduce illumination sensitivity issues is to use the Maximum Value Compositing (MVC) method, whereby the maximum NDVI value over a series of images is found (Bruzzone \& Smits, 2002). That way there is little effect from noise made by sensor angle differences and atmospheric scattering as it is presumed at least one image out of the set will hold accurate values.

In addition to using NDVI, the practice of applying threshold values to classify biomass into plant communities is common (Atkinson \& Treitz, 2012; Allen et al., 2012; Edwards \& Henry, 2016; Jones, 2015). Research by Lumbierres et al. (2017), supports the efforts of this MRP to determine the spatiotemporal trends of plant biomass through field verified success utilizing NDVI threshold values to identify vegetation. Threshold values in the Lumbierres et al. study were stratified into low, medium, and high grouped values of NDVI. Analysis comparing NDVI mean-variance was used to assess landscape vegetation (Lumbierres et al., 2017). The mean-variance method is used to test both the quantity or extent of vegetation, as well as the heterogeneity of the cover. Pixel-specific NDVI threshold values have also been tested in studies by Høgda et al. (2013), who found that NDVI threshold values were essential for determining vegetation differences in heterogeneous and sparse growth. Similarly, Edwards and Henry (2016) successfully use NDVI thresholds to monitor the climatic impact on three dominant plant community types in Nunavut; dry, mesic and wet. Vegetation communities in the Arctic tundra are very much defined by their moisture dependencies, so biomass levels and soil moisture are closely correlated (Edwards \& Henry, 2016; Laidler et al., 2008). Essential work was done by Laidler et al. (2008), to verify the connection of satellite derived NDVI values to plant community types by grouping NDVI values into low, medium, and high ranges in the Booth Peninsula, Nunavut. These studies show using NDVI thresholds to characterize three dominant vegetation community types types can be considerably successful for monitoring change. 
Perreault et al. (2017), used a threshold-based classification of NDVI to classify habitat types including wet and mesic environments in Nunavut. Although the classification accuracy of Perreault et al. was low, this was likely due to the wide spectral scale as wet and mesic environments were combined with many other classes (water bodies, sand, sparse vegetation), which likely lowered the success rate. Conversely, a Landsat derived vegetation map of Alaska identified 23 distinct heterogeneous land cover types, with a high degree of classification accuracy (Hall et al., 1998). In comparison to the study by Perreault et al., the success of Hall et al. was due to a method of stratifying classifications; by separating out different groups of land cover and performing unique classifications at each level. By isolating different land cover types before classification, the pixel distribution is reduced and classification accuracy can be increased. This MRP will utilize the method of masking out different classes such as water bodies and glacial area from the vegetated tundra to minimize the chance of misclassification. 


\section{CHAPTER THREE: DATA AND METHODOLOGY}

The overall methodology for this research involves two distinct components; calculating changes in glacial extent using NDSI, and determining trends in the tundra vegetation using NDVI. Since this is a time series analysis, the process of change detection will involve differencing the pixel values of two images to obtain a change image. This is done by differencing the values of images which are identical in extent and spectral type, but from different years.

The first component to determine the changes in glacial extent will utilize NDSI to highlight what glacialrelated changes have occurred. The NDSI method is a common approach for detecting glaciated landscapes, from which a difference image can be produced and classed into glacial loss and no change areas (Hall and Riggs, 2010).

The second component to determining landscape vegetation changes is more involved and utilizes the NDVI ratio. The NDVI will be calculated for each image to represent the amount of vegetation or biomass, which will then be classed into different plant community groups based on threshold values. These threshold values will identify three types of communities; low biomass (dry), moderate biomass (mesic), and high biomass (wet). Since moisture is a limiting factor in plant growth in the Arctic tundra, these plant community groups also correlate to moisture classes (Edwards \& Henry, 2016; Laidler et al., 2008). Image differencing will be performed on the NDVI classes to determine what areas, and to what extent change has occurred. Case study areas will be isolated for further analysis to look more in depth at what subclass changes may occurring.

\subsection{Data Acquisition and Processing}

\subsubsection{Climate Trends}

Climate data for Pond Inlet, Nunavut was utilized to show the historical patterns of temperature and precipitation over the last several decades. Data was downloaded from the Government of Canada's climate and weather historical data bank (GOC, 2017). The weather station was located at the Pond Inlet Airport $\left(77^{\circ} 58^{\prime} 08.000^{\prime \prime} \mathrm{W}, 72^{\circ} 41^{\prime} 22.000^{\prime \prime} \mathrm{N}\right)$. The data was downloaded as two different datasets; one containing the monthly climate information for 1976 - 2007, and the other containing the daily climate information from 2008 - 2016. One issue with this data source was the large amount of missing information. No records were kept prior to 1976, and especially in the later years, the value of precipitation was often unavailable. The closest station to Pond Inlet, which was Arctic Bay, Nunavut, was also missing the same data so no 
values could be supplemented. Although the climate data was not complete, the GOC source was the only option available containing the most historically complete and reliable climate data for Pond Inlet.

The annual summer temperature values were calculated by taking the average of the July and August monthly mean maximum temperatures (Figure 1.1). The total precipitation values were taken from the sum of July and August monthly precipitation values. Temperature and precipitation difference values were taken as the residual values from the 1976-1996 mean. Snowfall was calculated as the total amount of snowfall over a winter (from July to July).

\subsubsection{GIS Data}

To define the study area of Pond Inlet, a watershed boundary layer was obtained from personal communication with Dr. Dave Atkinson of the Polar Regions Spatial and Environmental Analysis Laboratory (Atkinson, pers comm.). The watershed layer was delineated using the hydrology toolset in ArcGIS from a DEM layer. The extent of all watersheds for Pond Inlet was used as the study bounds, and individual watersheds around the community of Pond Inlet were used for case studies. In addition, a shapefile package of the study area (Landsat footprint 029009) was downloaded from GeoGratis (hosted by Natural Resources Canada). Ancillary images were used from Google Maps (3D mode) to show the study area in Figure 1.2, as well as help to determine what the landscape features were.

A total of 4 cloud-free images were acquired for the Pond Inlet study site (Figure 3.1) from the Landsat Multispectral Scanner satellite series over the time period of 1989 - 2016 (Table 3.1). Remotely sensed imagery was acquired in Geotiff format through Earth Explorer, hosted by the United States Geological Survey. All images were preprocessed by USGS into Tier T1 data which indicates the images had proper geometric and radiometric quality through orthorectification and radiometric calibration procedures that ensure images are suitable for scientific use (USGS, 2017). Following data download, additional corrections were made to convert the image pixel values from digital numbers to physical reflectance values. The nature of time series change detection involves using multiple images from different times, and often different satellite sensors. Discrepancies between times and sensors occur from different illumination conditions, attributed to varying levels of atmospheric scatter and absorption (Silapaswan et al., 2001). Atmospheric scattering can vary from band to band, scattering inversely to the fourth power of the wavelength (Angelo, 2013). In addition, the degree of scattering is elevation dependent due to the thickness of atmosphere between the surface and the sensor (Burns \& Nolin, 2014); this indicates correction measures play an important role in mountainous environments. These discrepancies can cause images to become incomparable to one another (i.e. the inherent differences in the data values render the two sets unequal and 
not fit for inter-comparison). Huck et al. (2007), provide an in-depth analysis showing that this atmosphere effect on surface reflectance values needs to be corrected in order to use satellite imagery as a viable tool for analysis. By using the Top of Atmosphere (TOA) reflectance correction in Geomatica comparisons between multitemporal images will not be affected by different atmospheric conditions (PCI, 2010). This correction was made to all of the Landsat images following the procedures outlined in PCI Geomatica.

Vegetation grows according to predictable seasonal cycles based on moisture availability and temperature, where peak moisture levels from snow melt in the lower Arctic occur in the brief window of late July to early August. It is suggested that the most successful vegetation classifications will occur from imagery taken during the peak moisture seasons (Ozesmi \& Bauer, 2002). This is because classification errors sometimes occur due to the inability to separate the spectral signatures of vegetation and the surrounding terrain. During peak moisture times, vegetation becomes much healthier and darker, resulting in a higher spectral difference (contrast) than other land cover types (Høgda et al., 2013). Late July to early August is also coincident with the period of highest melt rates from high elevation ice caps. To get the most accurate glacial extent as well highest biomass, it was imperative to obtain images in this specific phenological state that capture the last stages of snow-melt and the maximum stages of plant growth.

Earth Explorer was searched to compile a list of any usable imagery in this season for all of the years available (1972 - 2016). The result was very limited as many of the images had heavy cloud cover, or did not cover the entirety of the study area. Also, a large data gap existed from sensor issues with Landsat 7 from 2005 to 2013. The resultant list only contained a handful of usable images, and images from 1989, 1997, 2005, and 2016 were chosen to create three time periods, each with a staggered gap of either 8 or 11 years apart. All bands used from the images had a resolution of 30 metres.

Table 3.1: Landsat image attributes downloaded from USGS Earth Explorer (USGS, 2017).

\begin{tabular}{|c|c|c|c|c|}
\hline Year & Satellite & Path/Row & Time & Scene Identifier \\
\hline 1989 & Landsat 5 (TM) & $029 / 009$ & July $26^{\text {th }}, 4: 30 \mathrm{PM}$ & LT50290091989207PAC00 \\
\hline 1997 & Landsat $5(\mathrm{TM})$ & 030/009 & July $23^{\text {rd }}, 4: 40 \mathrm{PM}$ & LT50300091997204PAC00 \\
\hline 2005 & Landsat 5 (TM) & 030/009 & August $14^{\text {th }}, 4: 57 \mathrm{PM}$ & LT50300092005226PAC00 \\
\hline 2016 & $\begin{array}{c}\text { Landsat } 8 \\
\text { (OLI/TIRS) }\end{array}$ & 030/009 & July $27^{\text {th }}, 5: 09 \mathrm{PM}$ & LC80300092016209LGN01 \\
\hline
\end{tabular}

The resulting images all show fair image quality, with little to no cloud cover. In addition to being in the same late summer stage, the images are also at approximately the same time of day (with less than an hour difference) which will help reduce solar and satellite orientation discrepancies. The four images were then imported into ArcGIS and clipped to the study area to obtain the subset images in Figure 3.1. The study 
area was defined as the area of the total watershed boundary for Pond Inlet. Further scene masking processes were performed which eliminated all ocean water, sea ice and some of the larger inland lakes. The 1997 image has noticeably much more sea ice than the other three years, showing that efforts to reduce the seasonal variability of the data was not fully successful. This upsurge of sea ice extent could be attributed to the colder than average summer temperatures for 1997 (Figure 1.1). Upon further inspection, the sea ice did not start reducing until August $1^{\text {st }}$ of 1997, and by August $15^{\text {th }}$ there was significant reduction that matched the extent in other years, however heavy cloud cover rendered the images unusable. This colder than average year may have implications on the level of vegetation present.

An additional consideration to note is the mixture of Landsat sensors used in this study (i.e. three images from Landsat 5 and one image from Landsat 8). Mixing sensor data products is common practice in multidecadal studies, as satellites have a limited lifespan (ex. Landsat 5 was retired in 2013). It is the intention that Landsat 8 satellite products be compatible to products from previous generation satellites (Flood, 2014). However, comparative analysis shows that there are some discrepancies between the wavelength range of each sensor, specifically, Landsat 8 bands have a much narrower range of wavelength values than Landsat 5 (Mandanici \& Bitelli, 2015; NRCan, 2015). Although a cross-comparison study by Li et al. (2014) report only minor differences between Landsat 5 and 8, other studies show that Landsat 8 sensors systematically overestimate NDVI (NDSI would follow the same trend) (Mandanici \& Bitelli, 2015; Roy et al., 2016). While this overestimation may be persistent, Flood (2014), reports that it only inflates the Landsat 8 values up to a maximum of $5 \%$. A regression transformation function can be used to reduce this overestimation, however it is location dependent and difficult to model (Roy et al., 2016). Therefore, the following analysis will not take into account any cross-sensor variance, as supported by Li et al. (2014), who confirms that the high linear correlation between sensors and minute index differences allow the imagery to be comparable. 

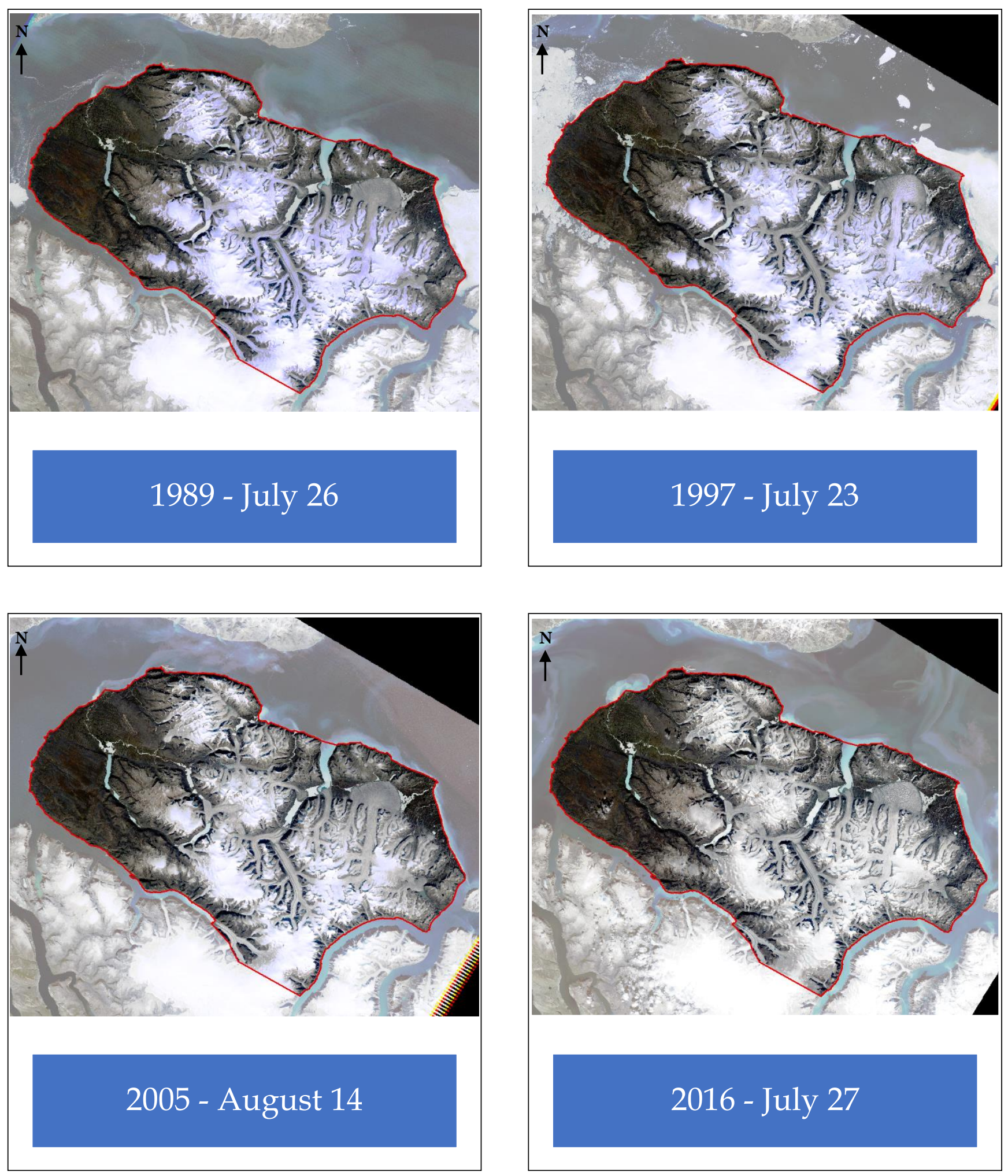

Figure 3.1: The processed image stack (1:600,000) for Pond Inlet, with the study area outlined in red. Images show a subset of Landsat Path 30, Row 9, downloaded from USGS Earth Explorer (USGS, 2017). 


\subsection{Glacial Change}

One of the primary objectives of this research is to determine the extent of glacial change throughout the time series. Introduced in Section 2.2, the NDSI method first tested by Dozier in 1989, was particularly useful in this setting to identify the spectral signatures of snow and ice from that of bare land. This method employs the green and near infrared bands. NDSI was calculated for each image using the Algorithm Librarian in PCI Geomatica with the following formulas;

$$
\begin{aligned}
& \text { NDSI }=(\text { Band } 2-\text { Band } 5) /(\text { Band } 2+\text { Band } 5) \text { for Landsat } 5 \\
& \text { NDSI }=(\text { Band } 3-\text { Band } 6) /(\text { Band } 3+\text { Band } 6) \text { for Landsat } 8
\end{aligned}
$$

Where bands 2 and 3 represent the green bands, and bands 5 and 6 represent the short-wave infrared bands.

An additional method to reduce classification errors was performed by applying a NDSI threshold value. This commonly used technique is to reduce the errors from rock, shadow or water that are included in the NDSI range. Literature, as introduced in Section 2.2, suggests a threshold value of 0.4 is appropriate which was found to be true in this study area through visual analysis. The threshold value was used to reclassify all pixels with a NDSI value of greater than 0.4 as 'Glacial', and all remaining values as 'Other'.

After generating the NDSI images, difference images were made for each time-step by subtracting the new image from the old image (i.e. 1997 - 1989, 2005-1997, 2016-2005). These difference images highlight the change in glacial extents, and were then reclassified into 'No Change' and 'Glacial Loss'. Glacial Loss was defined as any pixel with a negative change value where NDSI had decreased, and No Change was classified as all else. Note that the No Change class therefore includes all pixels that have increased in NDSI (added snow/glacier content), as well as pixels that have decreased in NDSI less than the threshold value (0 to 0.4 ). In Section 2.2 it was discussed that there can be limitations with the NDSI method overestimating glacial mass due to the contamination of snowpacks with glaciers. This limitation was exploited as any snow left at the end of the summer season was appropriately included as part of the Glacial type.

Although NDSI is good at detecting snow and ice, it also can frequently result in false positives from a mixture of rock, snow, and ice (Selkowitz \& Forster, 2015). Hall et al. (1998), explain that due to the band rationing of NDSI, it only takes a small percentage of visible reflectance to exceed the 0.4 threshold value when infrared reflectance is very low on a surface. In turn, this causes pixels to be erroneously classified as glacial features (Hall et al., 1998). To correct for this, a maximum likelihood supervised classification was performed to classify land cover types for the initial image of each time period. This land cover classification included four classes; snow/glacial features, inland water, shaded cliff sides, and other. Ocean 
water was extracted from a waterbodies shapefile from GeoGratis (NRCan, 2016). This shapefile was used to mask ocean water and sea-ice from the classification area, as well as a few large inland lakes. The shapefile was inspected for accuracy and any coastline discrepancies were addressed so no terrestrial glacial mass would be eliminated. This mask was used to reduce the possibility of classification errors by eliminating pixel variability in the image. This technique is common in reducing pixel classification errors such as in research by Jia and Epstein who also used also used a masking technique to eliminate coastal areas that would skew the pixel mixture (Jia \& Epstein, 2003; Lu et al., 2004). The same ocean mask was used for all four images, and carefully inspected each time to ensure no unwanted terrestrial glacial masking occurred. After each maximum likelihood supervised classification, an accuracy assessment was performed using 325 random stratified sample points. The accuracy assessment provides validation on how successful the classification was. The land cover classification was then combined with the NDSI change image to extract only areas where the land cover type was Glacial, and the change type was Glacial Loss.

Furthermore, a buffer was then created around the extremities of the Glacial land cover type to encapsulate only change at the glacial margins. This final step was performed to exclude single random change pixels that occurred across the broad accumulation zones due to reflectance differences that were not normalized between images. This method is consistent with many remote sensing studies, where filters are often used to reduce the 'salt-and-pepper noise' which is inherent in satellite imagery (Perreault et al., 2017; Selkowitz \& Forster, 2015). Van Wychen et al. (2016), who studied glaciers in Nunavut confirmed that glacial terminal fluxes can be used as an approximation for entire glacial motion (with some limitation), especially when elevation data is not available at the necessary temporal and spatial scale (Van Wychen et al., 2016). A distance of 330 meters was used for the buffer distance, as that was the greatest extent change that occurred, and each image was inspected to ensure no desired change pixels were lost.

The resulting area for every pixel found at glacial margins classified as Glacial Loss was then summed for each image to determine the total areal extent of glacial loss.

\subsection{Vegetation Change}

Determining vegetation change requires a more advanced methodology than determining glacial change, as glacial change is determined simply by differencing lateral extents (i.e. the recession or advancement of a glacier). Whereas vegetation change, measured by NDVI, requires an approach that takes into consideration changes in both vegetation extent, as well as shifts within the community composition. For example, hydrological inputs into a wetland have the potential to expand the wetland laterally (as more soil becomes saturated around the fringe) and increase vegetation by allowing for different species that require 
more moisture to grow. The methodology adopted for determining both of these changes is described in the following sections, and involves classifying vegetation community types, creating a difference image, and analyzing the variance in NDVI values for subclass shifts.

\subsubsection{Image Classification}

It has been suggested that remotely sensed NDVI values are strongly related to percent cover and ground biomass (see Section 2.3). As such, NDVI is the primary choice for classifying vegetation in the Arctic (Bhatt et al., 2010; Laidler et al., 2008; Stow et al., 2004). The NDVI ratio is based on the absorption of light in the visible spectrum and the reflectance of light in the near-infrared spectrum. Healthy vegetation absorbs more visible light and reflects more near-infrared, while sparse vegetation reflects more visible light and less infrared (Bhatt et al., 2010). NDVI was calculated for each layer using the Algorithm Librarian in PCI Geomatica with the following formulas;

$$
\begin{aligned}
& \text { NDVI }=(\text { Band } 4-\text { Band } 3) /(\text { Band } 4+\text { Band } 3) \text { for Landsat } 5 \\
& \text { NDVI }=(\text { Band } 5-\text { Band } 4) /(\text { Band } 5+\text { Band } 4) \text { for Landsat } 8
\end{aligned}
$$

Band 3 represents the red band, and band 4 represents the near infrared band in Landsat 5.

In Landsat 8, band 4 represents the red band and band 5 represents the near infrared band.

To reduce errors noted in previous studies of poor classification accuracy from the wide spectral range of pixel values; a mask was applied to cut out all ocean water, inland water bodies, glacial features and shaded cliff sides (Jia \& Epstein 2003; Perreault et al., 2017). This reduced the analysis extent to just the exposed tundra on the Pond Inlet lobe. The limiting of extent was used to reduce the spectral variability (reducing the range of NDVI values), as well as to remove areas that were not applicable to vegetation characterization. Shaded cliffs were removed due to the poor spectral signature emanating from the shaded area which leads to misclassification (Silapaswan et al., 2001). The mask was composed of the aforementioned land cover classes which were extracted from the classification output of the previous section (maximum likelihood supervised classification).

The remaining NDVI pixels in the Arctic tundra were grouped into three vegetation types; low NDVI values (dry), mid NDVI values (mesic), and high NDVI values (wetland). This method duplicates the threshold method introduced in Section 2.3 whereby vegetation cover in Arctic can be grouped into NDVI ranges. NDVI values are strongly correlated to percent cover as well as moisture levels, shown in a number of 
successful studies such as in Laidler et al. (2008) where Landsat derived NDVI values were validated with field measured values. The method employed by Laidler et al. found that the ranges of NDVI values represented three main vegetation community types, or moisture classes; dry (low biomass/NDVI: 0.08), mesic zones (moderate biomass/NDVI: 0.20-0.25), and wet zones (high biomass/NDVI: 0.35-0.45). Similar studies such as Edwards \& Henry (2016) or Olthof et al. (2008) use the same three Arctic moisture classes (wet, mesic, and dry) to group vegetation communities. The results of these studies provide the necessary background to adopt the same spectral grouping method.

The first image of the time series was assessed for these three groupings by using natural breaks in the NDVI values above 0 (vegetated areas). These were quite consistent with the grouping values used in Laidler et al. (2008). Table 3.2 shows the natural break values that were used to make the class ranges and their characteristics. The characteristics listed in Table 3.2 are intentionally limited to the observations from Laidler et al. (2008), due to comparable study areas. However, the common vegetation community characteristics also agree with other studies such as; increasing ecosystem wetness with higher NDVI values, higher graminoid and other vascular plant cover in high NDVI areas, as well as greater percent of lichen and forbs in lower NDVI areas (Edwards \& Henry, 2016) (Olthof et al., 2008).

Table 3.2: NDVI values for each community class with the associated characteristics derived from field studies performed in 2001, not far from Pond Inlet, Nunavut (Laidler et al., 2008).

\begin{tabular}{|c|c|c|}
\hline Class & NDVI Range & Community Characteristics \\
\hline Class 1 (dry) & $0-0.095$ & $\begin{array}{l}\text { Majority of cover is non-vegetated, and where } \\
\text { vegetation exists typically prostrate and } \\
\text { hemiprostrate dwarf shrubs }(<10 \mathrm{~cm}) \text { dominate } \\
\text { (ex. Saxifraga oppositifolia). Most areas will be } \\
\text { barren with dry, well-drained soil. }\end{array}$ \\
\hline Class 2 (mesic) & $0.095-0.25$ & $\begin{array}{l}\text { More continuous vegetation cover but still patchy, } \\
\text { typically comprising of prostrate and } \\
\text { hemiprostrate dwarf shrubs with increasing } \\
\text { graminoids and forbs. Soil holds moderate } \\
\text { amounts of moisture. }\end{array}$ \\
\hline Class 3 (wet) & $0.25-1.0$ & $\begin{array}{l}\text { Majority of cover is continuous vegetation (with } \\
\text { few non-vegetated patches), and graminoids (ex. } \\
\text { Pedicularis spp) are now dominant alongside } \\
\text { bryophytes. Most areas will have moist or wet soil } \\
\text { that is poorly drained. }\end{array}$ \\
\hline
\end{tabular}


The three grouping values for NDVI were then used to classify pixels values in all of the following time series images. Difference images were made for each time-step by subtracting the new image from the old image (i.e. 1997-1989, 2005-1997, 2016-2005). The difference image highlights the change between vegetation classes, of which there are seven possible outcomes (shown in Table 3.3). The area of each type of change was calculated from a pixel count to determine where vegetation types were being modified and what the change was.

Table 3.3: Possible change types between the images classed into dry, mesic, and wet NDVI groupings.

\begin{tabular}{cc}
\hline \hline Decreasing NDVI & Class Change \\
\hline Increasing NDVI & Wet to Dry \\
& Wet to Mesic to Dry \\
\hline- & Mesic to Wet \\
& Dry to Mesic \\
& Dry to Wet \\
\hline- & No Change \\
\hline
\end{tabular}

\subsubsection{Case Study Analysis}

To further develop this analysis, change was then analyzed on a more local level. The three classes of vegetation; Dry, Mesic, and Wet, were assessed for within-class changes for each year in the time series. This was intended to determine what specific shifts were happening at the subclass level that were inducing the overall changes. The particular sites chosen for additional analysis were the boundaries of watersheds surrounding the community of Pond Inlet. As mentioned in Section 2.2, the community of Pond Inlet obtains its drinking water from a meltwater fed pond. The ongoing quality and quantity of drinking water is being questioned, both at the local level (Aarluk Consulting Inc., 2011), as well as for drinking water across the Arctic (Alessa et al., 2008; NCCC, 2017). The watershed for this drinking water source is susceptible to upstream vegetation changes altering the quality and quantity of its hydrological inputs. The community of Pond Inlet often collaborates with researchers to undertake community based research and monitoring projects (Atkinson, pers comm.). These watersheds were chosen specifically because of their potential for drinking water use, as well as their accessibility for future field studies. The watersheds are shown in Figure 3.2 and from east to west are; Ivvisa watershed, Salmon Creek watershed (Quilalukat in the Inuit language) which contains the current drinking water pond, and New Water Lake watershed. 
The NDVI pixels for each watershed were extracted and the overall mean and standard deviation were calculated. This was done to confirm the overall trend of the watershed. Furthermore, the NDVI values of each class, in each year, were extracted for all three watersheds. These values were then analyzed with descriptive statistics for within-class shifts by using box-and-whisker plots. Excel was used to create boxand-whisker plots for each watershed depicting the class trends for each year. Box-and-whisker plots are common tools for indicating the spread and skewness of data, and are frequently used to investigate vegetation indices derived from spectral data (Andrade-Sanchez, 2014; Baldeck, 2013; De Jong, 1994). The mean, median, interquartile range, and outliers were compared for each class throughout the years to determine if more subtle within-class shifts were occurring.

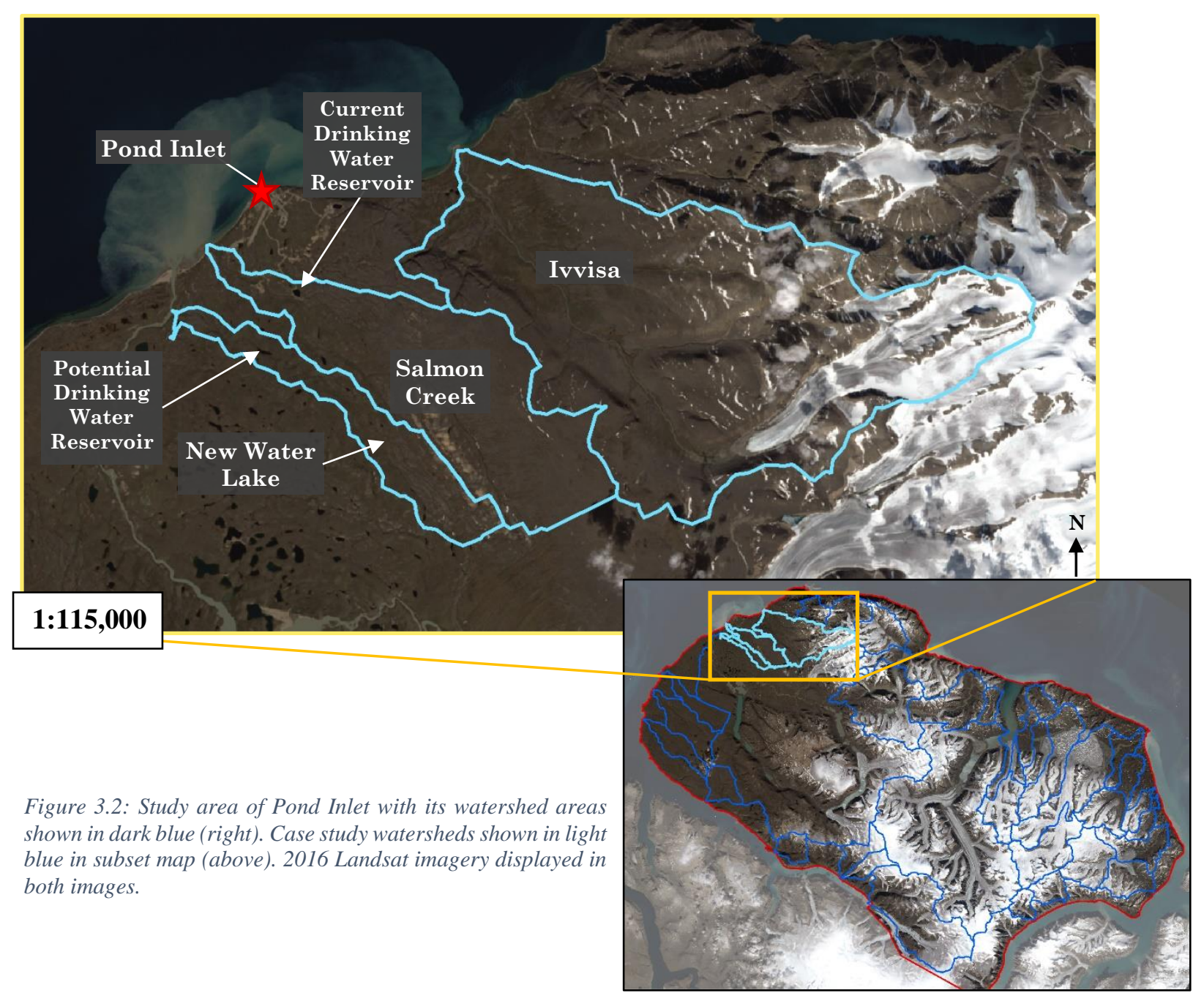




\section{CHAPTER FOUR: RESULTS AND DISCUSSION}

The results are divided into two sections according to the primary goals of this study; to determine the extent of glacial loss, and to determine the vegetation shifts that occurred in the Arctic tundra. A specific focus of the latter goal is the case study of watershed areas around the community of Pond Inlet, as this is a potential area for future research development. The results are followed by a discussion of all findings which attempts to draw connections to overall patterns and climate change.

\subsection{Glacial Change}

The NDSI method proved to be excellent at detecting glacial features, however significantly over classified additional land features. In particular, steep slopes and shadows were often incorrectly detected as Glacial Loss. The reclassification of the NDSI change layers with the land cover Glacial class generated by the supervised classification helped dramatically. The supervised classification using the maximum likelihood method was successful for all images and the accuracy assessment results are shown in Table 4.1. All classifications had over a 95\% accuracy, and as confirmed by the high Kappa coefficients, there is a high degree of validity. This success was likely due to the use of strong training sites as well as limiting the number of classes to three types (glacial, tundra, and shaded cliffs). All three classes had fairly distinct spectral signatures, resulting in a high degree of separability between classes.

Table 4.1: Accuracy assessment and Kappa statistics for the supervised land cover classification on each Landsat image.

\begin{tabular}{ccc}
\hline \hline Classified Image & Overall Accuracy & Kappa Statistic \\
\hline 1989 & $97.538 \%$ & 0.961 \\
1997 & $98.154 \%$ & 0.971 \\
2005 & $97.538 \%$ & 0.962 \\
2016 & $98.462 \%$ & 0.976 \\
\hline
\end{tabular}

Using the combination of Glacial Loss calculated from NDSI differencing and the Glacial land cover type from the maximum likelihood classification yielded the result of the glacial loss that was incurred through each time period. The limiting of this loss to only the terminal extents of glaciers was advantageous because of the variability that occurred over the interior glacial surface from spectral differences between years, such as small sections of debris cover. The loss of surface NDSI reflectance between years does not necessarily indicate the loss of the interior glacial quantity or quality. 
The resulting changes in extent show that from year-to-year there has been significant reduction of ice at the glacial margins. Shown in Figures 4.1, 4.2, and 4.3, the pixels in red illustrate where glacial margins have receded. Table 4.2 answers the first research question set out for this study by reporting the total areal extent of glacial loss.

Table 4.2: Results of marginal glacial loss from NDSI change detection.

\begin{tabular}{ccccc}
\hline \hline Time Period & Area of Glacial Loss & Area Loss/Year & Percent Loss/Year & Figure \\
\hline $1989-1997$ & $26.44 \mathrm{~km}^{2}$ & $3.3 \mathrm{~km}^{2} / \mathrm{yr}$ & $0.124 \%$ & Figure 4.1 \\
$1997-2005$ & $161.39 \mathrm{~km}^{2}$ & $20.2 \mathrm{~km}^{2} / \mathrm{yr}$ & $0.716 \%$ & Figure 4.2 \\
$2005-2016$ & $376.35 \mathrm{~km}^{2}$ & $34.2 \mathrm{~km}^{2} / \mathrm{yr}$ & $1.33 \%$ & Figure 4.3 \\
\hline
\end{tabular}

There is a significant trend of increasing area of glacial loss in each time period, with the most recent time period having over tenfold the yearly area loss of the initial time period $\left(3.3 \mathrm{~km}^{2} / \mathrm{yr}\right.$ to $\left.34.2 \mathrm{~km}^{2} / \mathrm{yr}\right)$. These dramatic losses in glacier area increase throughout the three time periods. These results are consistent with the trends over the whole Canadian Arctic as numerous studies express a pronounced increase of glacier mass loss in the last decade (AMAP, 2011; Gardner et al., 2012; Sharp et al., 2011). Overall, there has been a reduction from approximately $2670 \mathrm{~km}^{2}$ of glacier and snow pack area in 1989 to $2425 \mathrm{~km}^{2}$ in 2016 , an equivalent to $245 \mathrm{~km}^{2}$ net loss $\left(564 \mathrm{~km}^{2}\right.$ total loss, $319 \mathrm{~km}^{2}$ in snow/glacial addition). This is an average glacial loss of approximately $20 \mathrm{~km}^{2} /$ year over the entire time series. The subset images provided in Figures $4.1,4.2$, and 4.3, show a particularly interesting case of marine-terminating glaciers alongside valley glaciers with spreading ablation zones. The contrasting terminus settings all show ice wastage at their margins, which is naturally expected as thinner sections of glacier should disappear first. One key issue shown in the data is the maximum melt period offset for 1997. Discussed in Section 3.1.2, and shown in Figure 3.1, the image for 1997 had more snow cover than desired due to a delayed melt. This resulted in a greater level of snow cover, meaning higher values of NDSI. Therefore, this likely superficially lowered the percent of glacial loss from 1989 to 1997, as well as increased the percent of glacial loss from 1997 to 2005. 

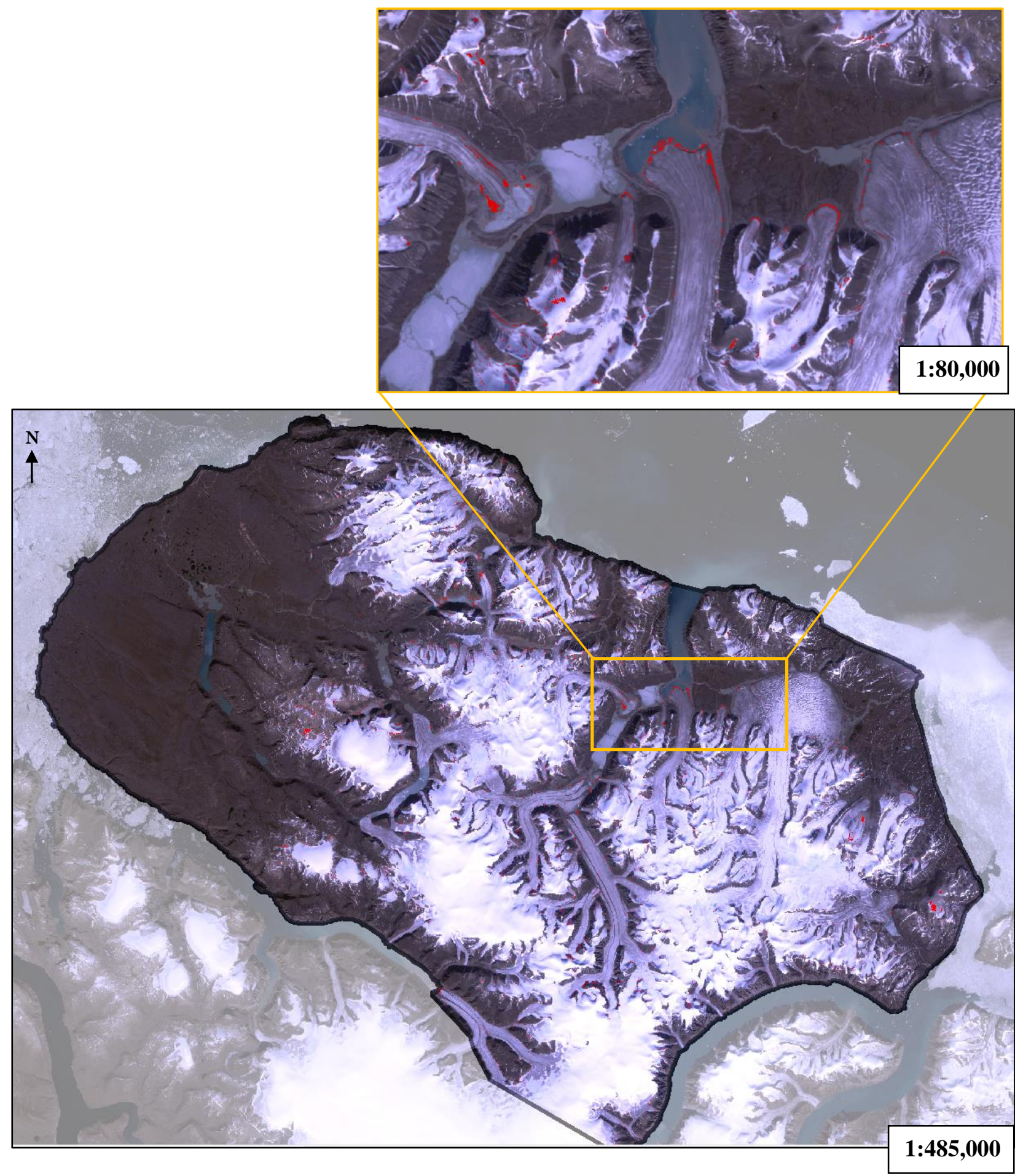

Figure 4.1: The resulting glacial loss (shown in red) calculated from NDSI differences from 1989 to 1997. 

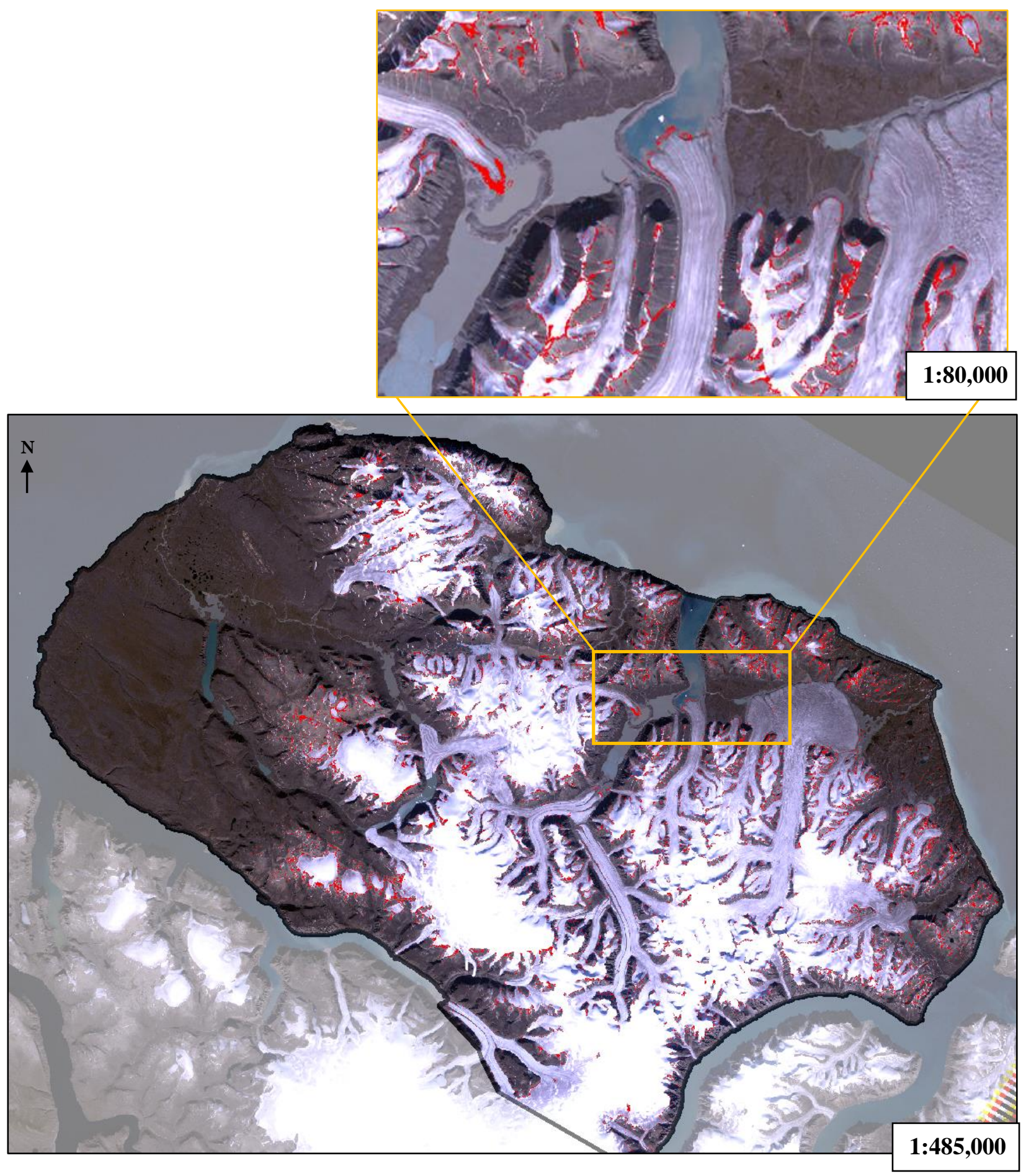

Figure 4.2: The resulting glacial loss (shown in red) calculated from NDSI differences from 1997 to 2005. 

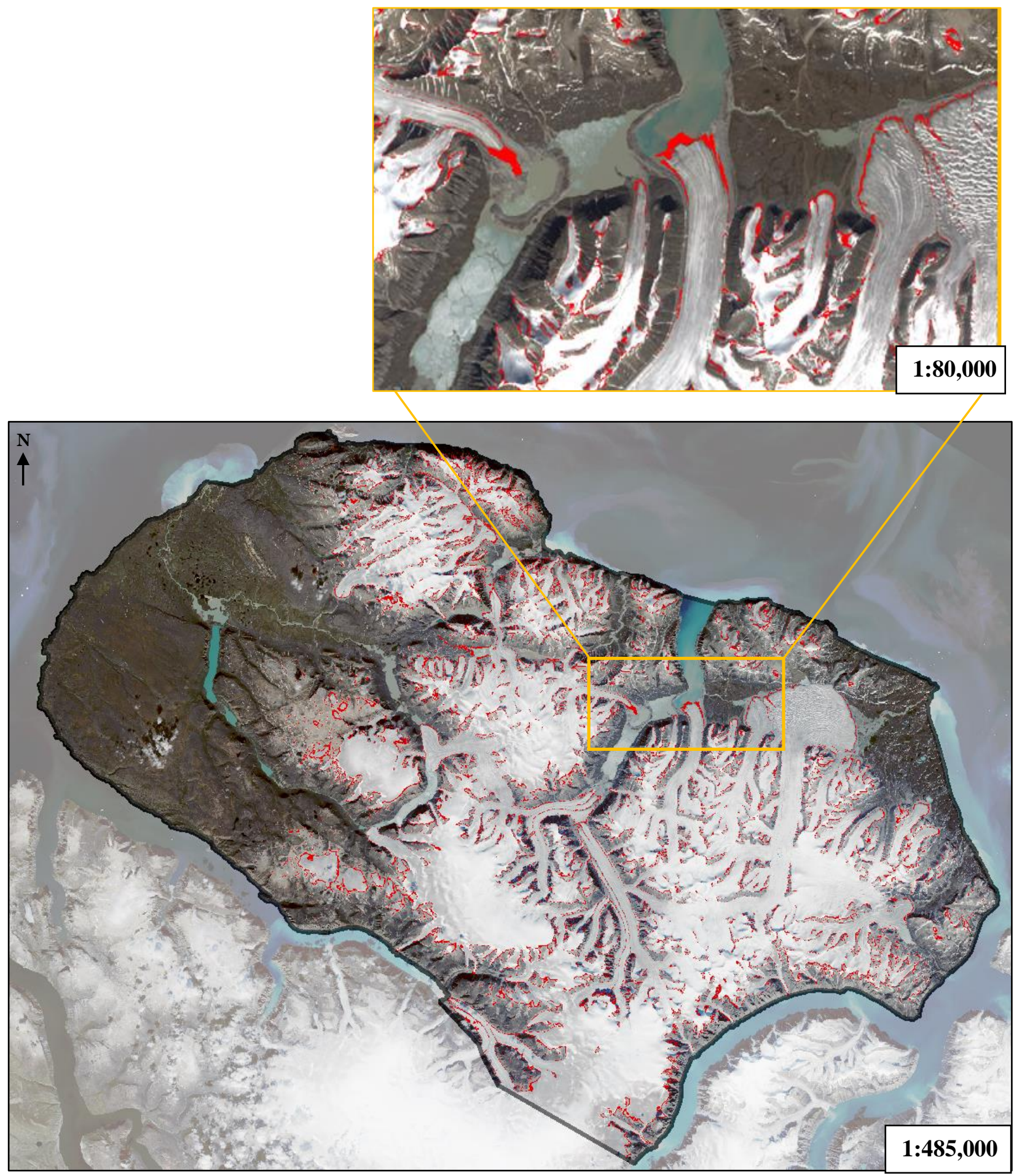

Figure 4.3: The resulting glacial loss (shown in red) calculated from NDSI differences from 2005 to 2016. 


\subsection{Vegetation change}

By classifying the NDVI values in each image into three dominant vegetation communities an estimation of each cover type was formed. Table 4.3 shows the distribution of classified pixels into each vegetation group as well as the overall image statistics. The mean NDVI value for each year steadily increases, with a notable jump in 2016. This pronounced increase in NDVI values for 2016 parallels the Arctic 'greening' trend in the last decade that has been noted by many other authors (Jia \& Epstein, 2003; Silapaswan et al., 2001; Stow et al., 2004). In addition, the standard deviation is also generally increasing, with the exception of 1997, indicating not only are pixel values increasing, but they are becoming more variable as well. The lower standard deviation in 1997 could be a result of the lower temperatures and longer snow cover (as previously described in Section 3.1.2 and 4.1), inhibiting vegetation from reaching its fullest state. This is one of the limitations of the data as the peak phenology for each year, specifically 1997, was not captured.

The majority of pixels (48\%) in the first image (1989), were assigned to Class 1, indicating they had a NDVI value of 0-0.09. Class 3 had the least amount of assigned pixels (25\%), indicating there were fewer pixels with a NDVI over 0.25 . As each image in the time series progresses, there is a shift in the percentages of pixels moving towards the highest class. By the final image (2016), there is only $42 \%$ of pixels with a NDVI value below 0.09 , and $32 \%$ of pixels with a NDVI value above 0.25 . This suggests a general 'greening' movement into wetland vegetation communities as the higher NDVI class is favoured in the later images. Class 2 has a more subtle trend, where there is less of a change in class percentages. This is likely because of a balance in the flux of pixels transferring in from Class 1, and moving out into Class 3 . Analysis of the individual class statistics will reveal if these assumptions are indeed accurate, and then further case studies will show the trends at the subclass level.

Table 4.3: Global class distribution of NDVI groupings per year.

\begin{tabular}{ccccc}
\hline \hline Year & Mean (Standard Dev) & Pixel \% in Class 1 & Pixel \% in Class 2 & Pixel \% in Class 3 \\
& & $0-0.095$ & $0.095-0.25$ & $0.25-0.1$ \\
\hline 1989 & $0.140(0.124)$ & $48.30 \%$ & $27.07 \%$ & $24.63 \%$ \\
1997 & $0.149(0.119)$ & $46.67 \%$ & $28.93 \%$ & $24.40 \%$ \\
2005 & $0.152(0.130)$ & $47.85 \%$ & $26.22 \%$ & $25.93 \%$ \\
2016 & $0.181(0.150)$ & $41.52 \%$ & $26.80 \%$ & $31.68 \%$ \\
\hline
\end{tabular}



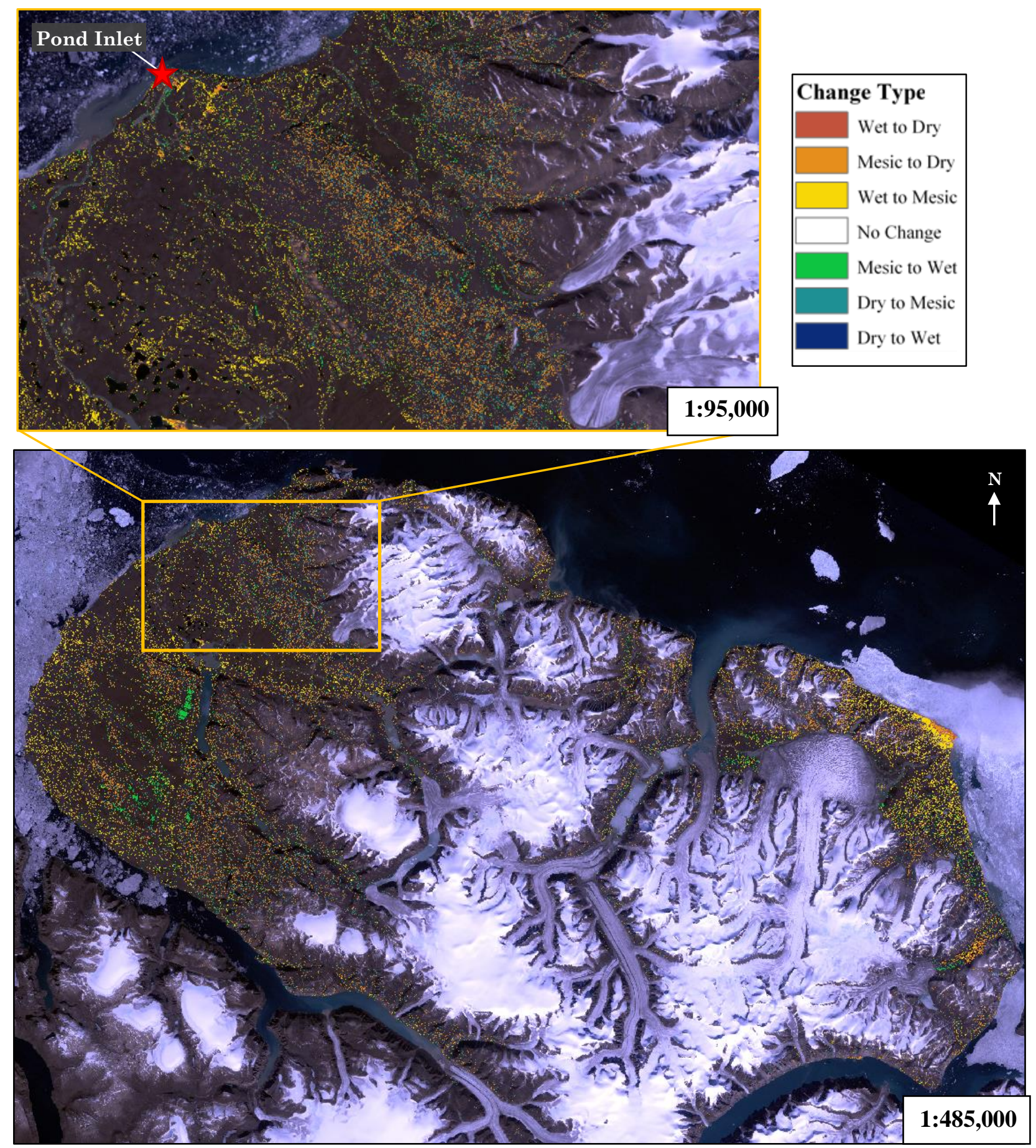

Figure 4.4: The resulting vegetation changes calculated from differencing NDVI classes from 1989 to 1997. Subset image shows the location of the community of Pond Inlet. 

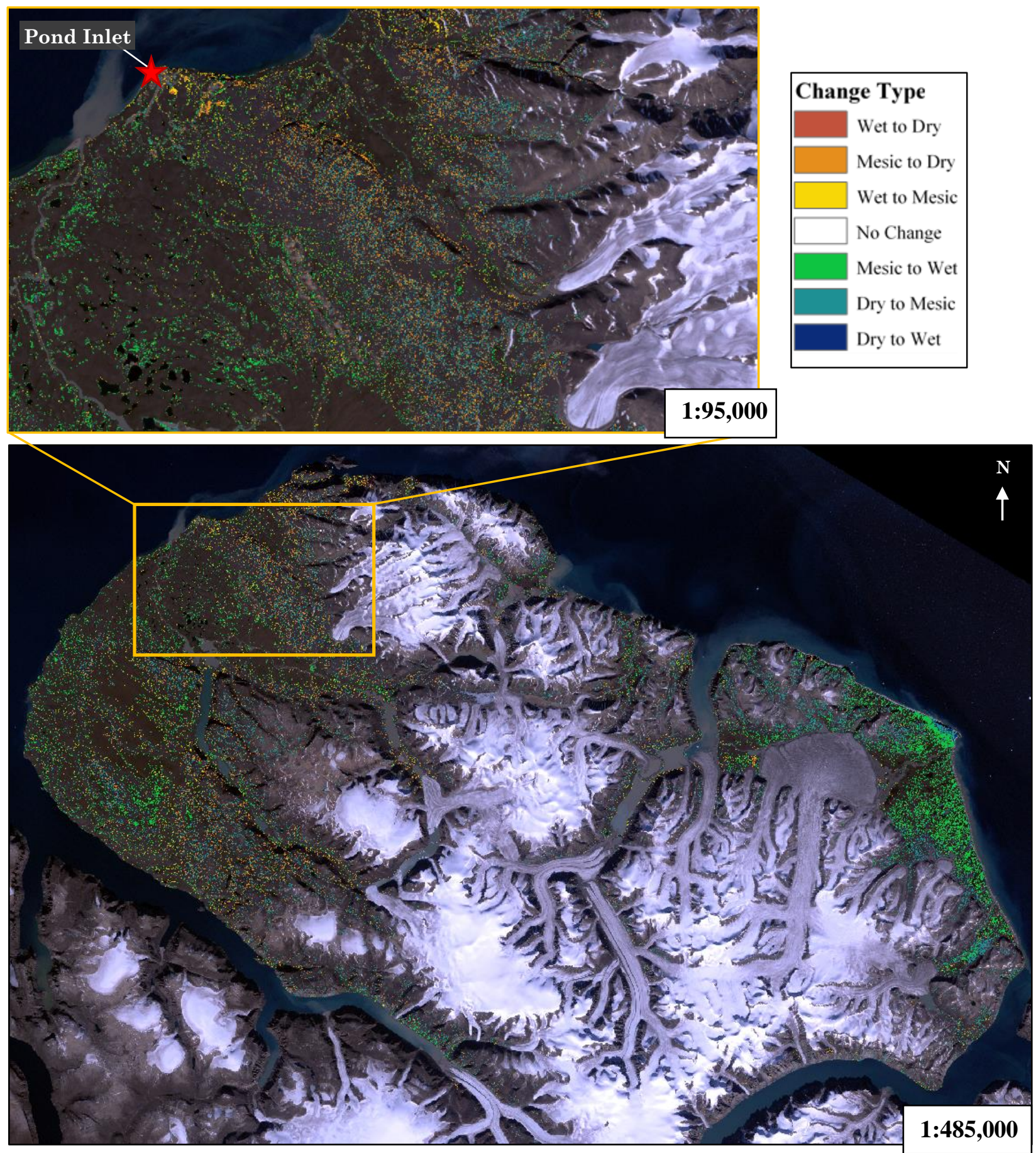

Figure 4.5: The resulting vegetation changes calculated from differencing NDVI classes from 1997 to 2005. Subset image shows the location of the community of Pond Inlet. 

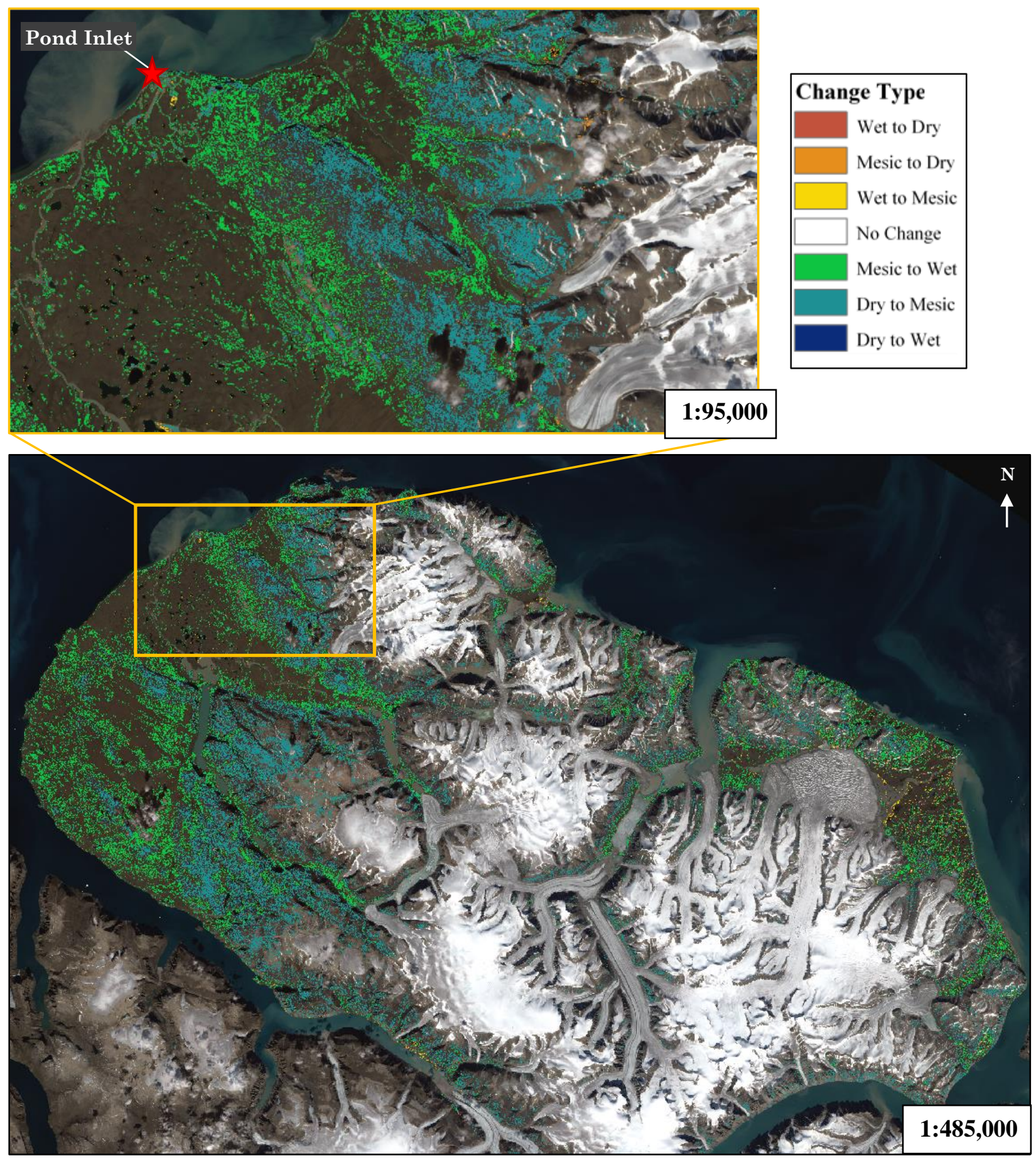

Figure 4.6: The resulting vegetation changes calculated from differencing NDVI classes from 2005 to 2016. Subset image shows the location of the community of Pond Inlet. 
Table 4.4: Global NDVI class changes depicted in the difference image from 1989 to 1997. Accompanying Figure 4.4.

\begin{tabular}{ccccc}
\hline \hline & Class Change & Pixel Count & Change Percent & Area $\left.\mathbf{( k m}^{\mathbf{2}}\right)$ \\
\hline Decreasing & Wet to Dry & 1378 & $0.45 \%$ & 1.24 \\
NDVI & Mesic to Dry & 125565 & $40.81 \%$ & 113.01 \\
& Wet to Mesic & 97982 & $31.84 \%$ & 88.18 \\
\hline Increasing & Mesic to Wet & 32787 & $10.65 \%$ & 29.51 \\
NDVI & Dry to Mesic & 49969 & $16.24 \%$ & 44.97 \\
& Dry to Wet & 35 & $0.01 \%$ & 0.03 \\
\hline- & No Change & 2437941 & - & 2194.15 \\
\hline
\end{tabular}

Table 4.5: Global NDVI class changes depicted in the difference image from 1997 to 2005. Accompanying Figure 4.5.

\begin{tabular}{ccccc}
\hline \hline & Class Change & Pixel Count & Change Percent & Area $\left(\mathbf{k m}^{2}\right)$ \\
\hline Decreasing & Wet to Dry & 169 & $0.05 \%$ & 0.15 \\
NDVI & Mesic to Dry & 59713 & $17.39 \%$ & 53.74 \\
& Wet to Mesic & 24179 & $7.04 \%$ & 21.76 \\
\hline Increasing & Mesic to Wet & 122008 & $35.53 \%$ & 109.81 \\
NDVI & Dry to Mesic & 135522 & $39.47 \%$ & 121.97 \\
& Dry to Wet & 1760 & $0.51 \%$ & 1.58 \\
\hline- & No Change & 2345609 & - & 2111.05 \\
\hline
\end{tabular}

Table 4.6: Global NDVI class changes depicted in the difference image from 2005 to 2016. Accompanying Figure 4.5.

\begin{tabular}{ccccc}
\hline \hline & Class Change & Pixel Count & Change Percent & Area $\left.\mathbf{( k m}^{2}\right)$ \\
\hline Decreasing & Wet to Dry & 819 & $0.11 \%$ & 0.74 \\
NDVI & Mesic to Dry & 12756 & $1.74 \%$ & 11.48 \\
& Wet to Mesic & 5701 & $0.78 \%$ & 5.13 \\
\hline Increasing & Mesic to Wet & 300841 & $41.01 \%$ & 270.76 \\
NDVI & Dry to Mesic & 411982 & $56.17 \%$ & 370.78 \\
& Dry to Wet & 1404 & $0.19 \%$ & 1.26 \\
\hline- & No Change & 2218791 & & 1996.91 \\
\hline
\end{tabular}


To answer the second question of this research project - what are the resulting vegetation shifts occurring, a mix of maps and statistics tables are needed. The above maps are best used for location based analysis and visually interpreting areas of change, while the accompanying statistic tables (Table 4.4, 4.5, and 4.6) show the precise numerical trends.

\subsubsection{Global Vegetation Change for 1989 to 1997}

Beginning with the time period from 1989 to 1997, there was 11\% change within the Arctic tundra, or 277 $\mathrm{km}^{2}$ that had switched vegetation classes. This is an average change of $1.38 \%$ per year. Within this change, there can be seen an overall decrease in NDVI values. Table 4.4 shows that there is a higher percentage of pixels moving into lower classes (73\% total) than there are pixels moving into higher classes (27\%). This indicates that at the class level, NDVI values are decreasing across the class thresholds ( 0.09 and 0.25$)$. The majority of this decrease is from Class 2 to Class 1, or from the Mesic to Dry vegetation communities. Figure 4.4 illustrates this with the scattering of orange change pixels throughout the Arctic tundra. Much of this change seems to be in the areas closest to glaciers, with fewer change pixels in the open and flat tundra areas, however, all the loss pixels have fairly even dispersion and specific spatial patterns would have to be investigated at finer scale. There is an anomaly on the eastern Arctic coast, where a clustering of decreasing change pixels collect. Looking closer at the source images, this is due to some light cloud cover in the 1997 image, offsetting the NDVI values. This area must therefore be overlooked as NDVI values from 1997 will not be representative of underlying vegetation. This significant clustering area likely has a substantial influence on the percentage of decreasing NDVI values, superficially inflating the proportion of this type of change.

Some spatial trends occur in the amount of pixels increasing in NDVI. The area of change that moves from Mesic to Wet $\left(29.5 \mathrm{~km}^{2}\right)$, can be seen clustered in a N/S trajectory parallel to one of the main glacier fed lakes. The areas shifting from the Dry to Mesic class also show some spatial trends. Illustrated in a teal colour, most of these change pixels are congregated around the foothills of glaciers. In the subset image of Figure 4.4, there is a discernable segregation of these Dry to Mesic pixels in a SW to NE gradient, where

highest concentrations occur below the glaciers (presumably in their melt water path), and lowest concentrations in the central tundra.

Important to note are the very small values for the most extreme changes (Wet to Dry or Dry to Wet). This result strengthens the analysis, as this type of change between vegetation extremes is most unlikely and it would be expected that the percentage of change should be small. This statement holds true for all of the following time series images. 


\subsubsection{Global Vegetation Change for 1997 to 2005}

In the 1997 to 2005 time period, 13\% of pixels are identified as change pixels, compared to the initial time period image with only $11 \%$ (Table 4.5 ). This is an average change of $1.63 \%$ per year, compared to $1.38 \%$ in the first time period. Out of these change pixels, $24 \%$ shift into lower NDVI classes in contrast to $76 \%$ of change pixels which move up to classes with a higher NDVI. This percentage equates to $\sim 309 \mathrm{~km}^{2}$ area of change, an increase of $32 \mathrm{~km}^{2}$ from the initial time period. From Figure 4.5, there is a clear transition to more increasing values of NDVI as more pixels show green (Mesic to Wet), or teal (Dry to Mesic) colours. There is an overall 'greening' of the image, with strong trends in the eastern section of the image that border the coast. From a visual analysis of the underlying image, this eastern area appears to be a relatively low lying area of outwash plains, filled with braided streams made from meltwater coming off a multitude of glacier lobes which pour down from the mountains. This area is dominated by the Mesic to Wet change type, which is consistent with the visual analysis as it is clearly an area with already established water inputs. The dense grouping of change pixels suggest that much of the area has collectively increased in NDVI, compared to the more isolated change pixels found elsewhere in the image. Most of the broad open tundra south of the community of Pond Inlet is filled with these single isolated change pixels. In this area, change type varies from increasing to decreasing classes of NDVI, with a modest bias towards increasing class changes.

A continuing trend from the initial time period image is that the location of the Dry to Mesic classes are often located in foothills bordering glaciers. Similar to the subset image in Figure 4.4, the pixels in this Dry to Mesic change class can be seen beneath the glacier lobes, with a NW to SE alignment (Figure 4.5). Interestingly, they are also dispersed among a number of Mesic to Dry classes, indicating this area is not stable and may have frequently fluctuating environmental conditions.

\subsubsection{Global Vegetation Change for 2005 to 2016}

Change between 2005 and 2016 was most dramatic out of all three time periods. The percent of changed pixels doubled from the previous time period to result in a 25\% change within the Arctic Tundra, or $~ 660$ $\mathrm{km}^{2}$. This equates to an average change of $2.27 \%$ per year. Table 4.6 shows that almost all (97\%) of the change pixels are moving from lower vegetation classes to higher classes. This equates to $\sim 643 \mathrm{~km}^{2}$ of tundra that is increasing in pixel value past a class threshold, compared to a mere $\sim 17 \mathrm{~km}^{2}$ that was decreasing. This change is apparent in Figure 4.6, where almost all change pixels appear to be in the Mesic to Wet, or Dry to Mesic categories. 
Some distinct patterns emerge from this image as it is clear that the Mesic to Wet and Dry to Mesic change types have some unique spatial characteristics. The Mesic to Wet change type frequently appears in the open tundra areas, or in what might be more low-lying areas. This is a logical inference as it is most likely that lower elevation areas receive and store more moisture, and therefore generate more vegetation. The open tundra adjacent to the community of Pond Inlet has most of the Mesic to Wet change type. The Dry to Mesic change type has a clear clustering to areas adjacent glaciers- strongly apparent in this image, but also an emerging trend from the last two times periods. This change type also has logical positioning, as areas close to glaciers likely experience the most ice scouring or heavy winter snowpack as the glacier advances in the winter and clears out the underlying vegetation. Therefore, the base NDVI values should be fairly low for these areas, as rock has a very low NDVI. The change from Dry to Mesic vegetation communities indicates higher NDVI values, which could be a result of many landscape changes such as; early glacier retreat in the spring allowing more vegetation to flourish, less dense snowpack through the winter allowing some types of vegetation to persist, or increased hydrological inputs turning a water restricted ecosystem into a wetter one - thereby increasing vegetation.

There is also a pattern of No Change occurring, present in all three time periods but most obvious in the later one, whereby there are several NW/SE striations of no change in the open tundra south of the community of Pond Inlet. It is unclear on what is causing these consistent areas of no change, but there are likely some underlying geological differences. There is also an area that has infrequent change throughout the three time periods, located to the south of the community of Pond Inlet, and extending along a river(NW/SE) leading from one of the central outlet glaciers. It is somewhat expected that riverside areas would exhibit prominent changes, specifically along their banks, assuming hydrological additions from increased glacier melt are allowing for more vegetation growth. This, however, is not the case for this area of No Change. It is possible that there is already a high NDVI value from established vegetation, and there is no additional threshold to cross to show increases.

The nature of the categorical variables to represent vegetation type limit the amount of change that can be shown. Inherently, no area can show unidirectional change for more than two time periods in a row, before there are no additional class thresholds to breach. Since the categorical variables (specifically Class 3 ) have fairly large ranges, it is possible that change can be occurring within a class, and therefore not detected in a class difference image. To solve this issue, the subclass NDVI trends are analyzed in the following case studies. 


\subsection{Case Study Analysis}

The three watersheds used for additional analysis can be seen in Figure 3.2. These watersheds are close to the community of Pond Inlet, and are of specific interest due to their potential for drinking water, as well as future research sites. Each watershed was analyzed individually for watershed trends, as well as for underlying pixel movement within each class.

\subsubsection{Ivvisa Watershed Analysis}

The most northerly watershed used for case study analysis was the Ivvisa watershed (Figure 4.7). It is the largest watershed of the three, with an area of $138 \mathrm{~km}^{2}$. It encompasses a large section of Arctic tundra, with a few terminal glacier lobes flowing down from the mountains in the east. The most prominent glacial lobe leading into the tundra valley produces a meltwater filled river that leads out to the Arctic Ocean. This river collects a minimum of two additional tributaries that flow down from the mountains before it reaches the coast. A shaded hillside (running NW to SE) in the 2016 Landsat image indicates there is a central low elevation valley (containing the river system previously mentioned) with a higher elevation plateau to the southwest, and the mountain foothills to the east. Note that the 2016 imagery has some cloud cover which was masked for analysis.

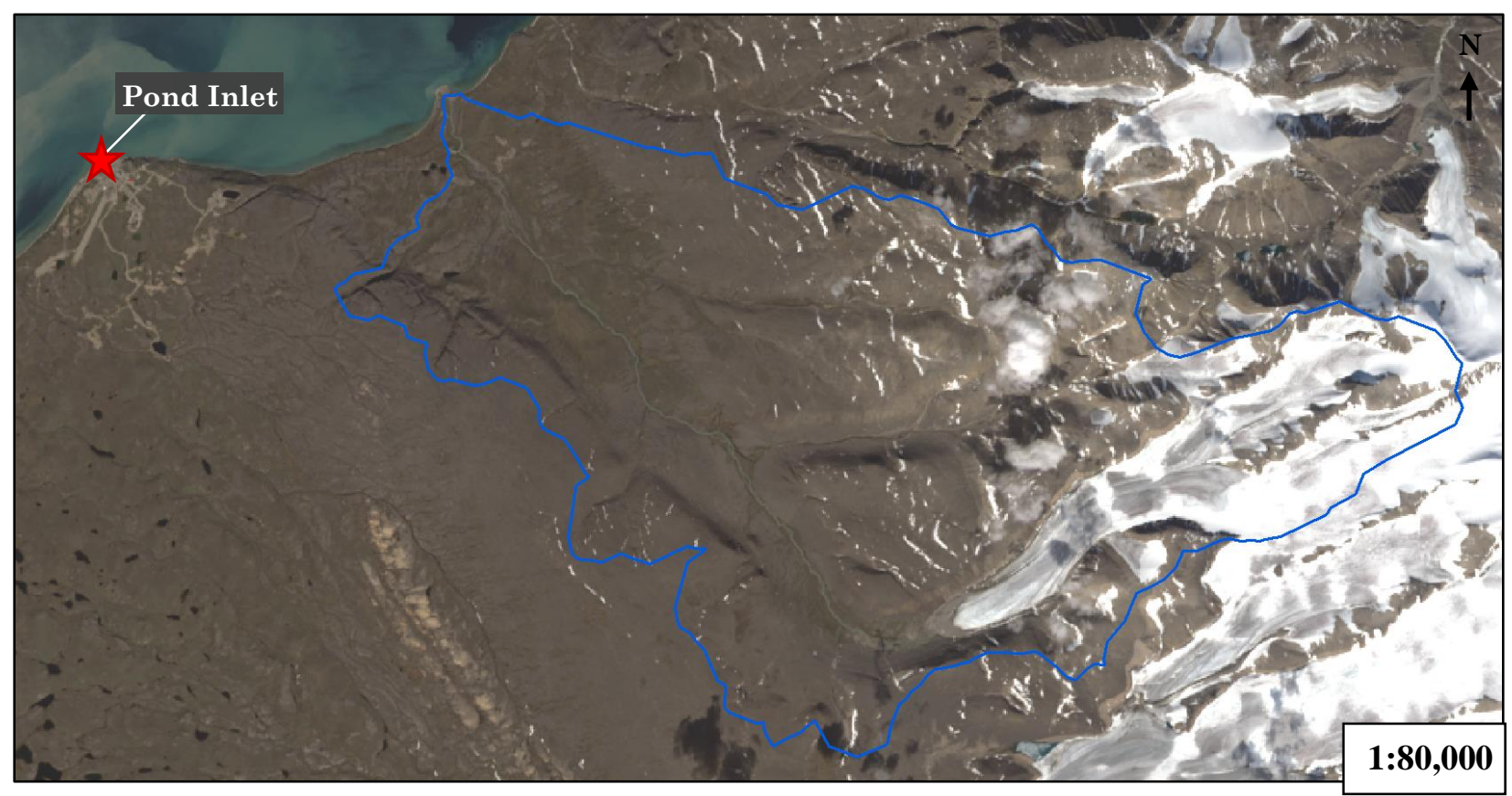

Figure 4.7: An overview of the Ivvisa watershed (blue) displayed on the 2016 Landsat imagery. 
Figure 4.8 shows the trends of class change throughout the time series. There is a clear spatial pattern in the first two time periods between the Mesic and Wet vegetation communities in the central valley trough, whereas the bordering higher elevation areas show shifts between Mesic and Dry communities. This is consistent with knowledge that higher elevations have less vegetation due to lower temperatures, as well as moisture restrictions (Laidler et al., 2008; Raynolds \& Walker, 2016; Woo \& Young, 2006). Table 4.7 shows the yearly trends for the Ivvisa watershed. The mean NDVI values between the years in the first two time periods remain relatively consistent $(0.133-0.136)$. Similarly, the percentage of pixels in each class have little variation $(<5.2 \%)$. Yet, within these time periods, a total of $11-12 \%$ of pixels shift classes. The combination of both class shifts occurring and class percentages remaining the same, indicates that there must be a similar amount of pixels transferring between the same two classes. These shifts could indicate fluctuating vegetation conditions, or they could also indicate that pixels cluster around the threshold points between classes, and potentially subtle reflectance changes could push them into one class or another.

The final time period image resulted in both a much greater amount of change (31\% of pixels classified as change), as well as a shift in the type of change (99\% of change is moving to higher classes). Most significantly, there is an abrupt change in the 2016 image where $22 \%$ of pixels shift from the Dry to Mesic class, and $8 \%$ shift from the Mesic to Wet class. The large area of change from the Dry to Mesic class can be seen lining the foothills of the higher elevation areas (Figure 4.8). Whereas the areas of change for the Mesic to Wet class are mostly in the outskirts of the lower valley. The inner valley consistently does not show much change, likely because it has already established vegetation and NDVI movement is occurring within a class (i.e. the vegetation type falls within Class 3 to start, and so increased vegetation trends leading to higher NDVI values are not detected). To determine these within-class movements, box-and-whisker plots are used. The box-and-whisker plots are key to determine if these class changes are valid vegetation community shifts, or if they are just a consequence of using categorical variables to model continuous data.

Figure 4.9, shows the box-and-whisker plot for the Ivvisa watershed. Analyzing Class 1 reveals that there are similar pixel distributions for all four years. In this class, the medians are all consistent with the mean, indicating that all years have a symmetric distribution and should be fairly stable. To support this, the values of the median, mean, and interquartile ranges (IQR) are approximately the same between years, showing low year to year variability. Class 2 reveals that although the IQRs and means are mostly consistent from 1989 to 2005, the mean values are greater than the medians (especially in 2005). This shows an underlying skewed distribution (to the right), and from the unequal tail lengths, the values in Class 2 are clustered much closer to the threshold border with Class 1 . The short range of the first quartile in conjunction with the low median value indicates that there is a high likelihood that pixels can be easily 
switched between Class 1 and Class 2 with only small changes in NDVI value. This echoes the observations noted above from Figure 4.8 and Table 4.7, where there was a high amount of transfer between the Dry and Mesic classes. The 2016 pixel distribution for Class 2 shows a shift in the interquartile range, where pixel values are collectively higher, reducing the possibility of insignificant Class 1 to Class 2 transfers.

Moving up to Class 3, there is an increase in dispersion of the class distributions between all years. There are a number of outliers far above the fourth IQR from 1989-2005 which show a right skewed distribution. The location of these outliers was investigated and most are related to the coastal area, or interior depressions where stream tributaries collect. These areas would have more moisture availability so vegetation would be highest. Stow et al. (2004) come to the same conclusions that in the Arctic tundra water collects in topographic depressions, promoting plant growth and increasing NDVI. The Class 3 grouping for the 2016 image shows a pronounced increase in the IQR, median, and mean with few outliers. This, along with a higher median than mean, suggest that many of the 2016 NDVI values in Class 3 have collectively increased in value, into the range of the upper third quantile.

To summarize the findings of the statistical analysis of the Ivvisa watershed, there is a strong possibility that the movement of pixels between the Dry and Mesic vegetation types is due to a lack of separability between classes. This finding is also supported by the fairly consistent mean, median and IQRs between years for Class 1 and Class 2. Class 3 however, shows some increase in the variation of pixel distribution from 1989 to 2005, and significant increase both in the pixel values as well as variation for 2016. This implies the shifts between the Mesic and Wet vegetation communities are likely more meaningful and represent significant increases in pixel NDVI value. 
Table 4.7: Watershed NDVI Properties for the Ivvisa Watershed

\begin{tabular}{ccccc}
\hline Year & Mean (Standard Dev) & Pixel \% in Class 1 & Pixel \% in Class 2 & Pixel \% in Class 3 \\
& & $0-0.095$ & $0.095-0.25$ & $0.25-0.1$ \\
\hline 1989 & $0.134(0.113)$ & $46.75 \%$ & $34.95 \%$ & $18.30 \%$ \\
1997 & $0.133(0.115)$ & $42.48 \%$ & $37.03 \%$ & $20.49 \%$ \\
2005 & $0.136(0.121)$ & $47.69 \%$ & $33.38 \%$ & $18.93 \%$ \\
2016 & $0.181(0.137)$ & $28.42 \%$ & $45.85 \%$ & $25.73 \%$ \\
\hline
\end{tabular}

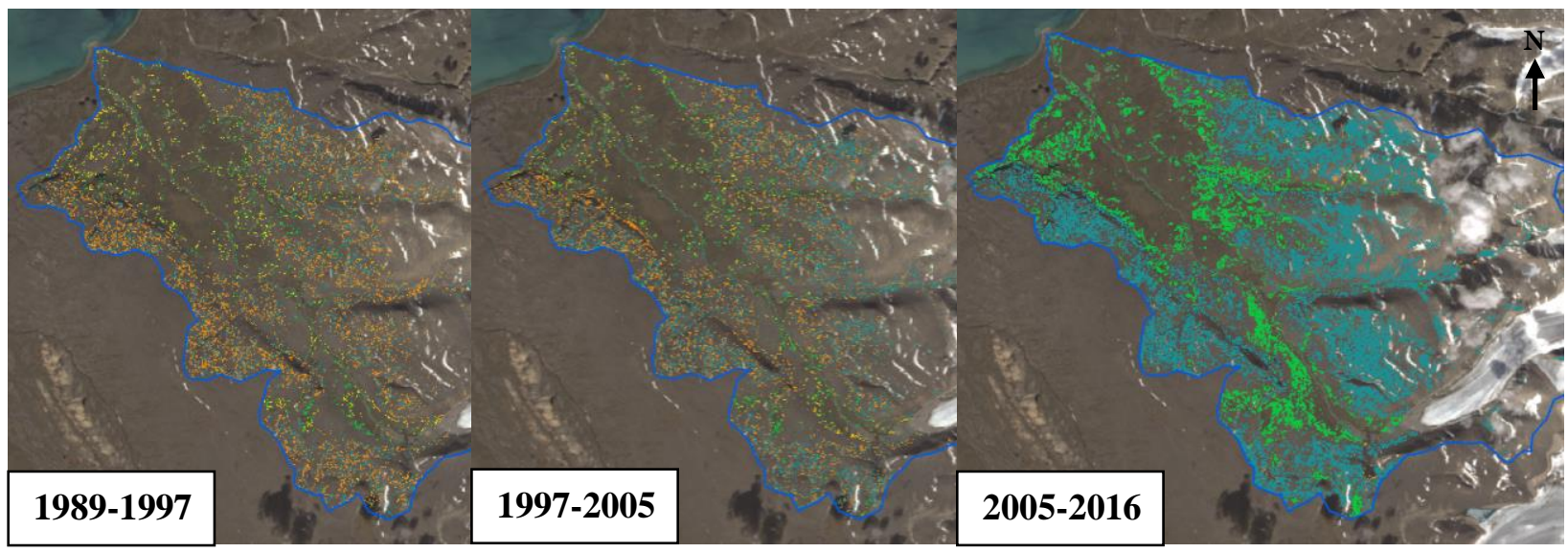

Figure 4.8: Time series trends in vegetation classes for the Ivvisa watershed. Red/orange hues are time shifts towards decreasing NDVI classes, green/blue hues are shifts towards increasing NDVI classes.

Table 4.8: Pixel change distribution for the Ivvisa Watershed

\begin{tabular}{ccccc}
\hline \hline & Class Change & $\begin{array}{c}\text { Percent Change for } \\
\mathbf{1 9 8 9 - 1 9 9 7}\end{array}$ & $\begin{array}{c}\text { Percent Change for } \\
\mathbf{1 9 9 7 - 2 0 0 5}\end{array}$ & $\begin{array}{c}\text { Percent Change for } \\
\mathbf{2 0 0 5 - 2 0 1 6}\end{array}$ \\
\hline Decreasing & Wet to Dry & $0.00 \%$ & $0.00 \%$ & $0.00 \%$ \\
NDVI & Mesic to Dry & $5.83 \%$ & $4.50 \%$ & $0.40 \%$ \\
& Wet to Mesic & $1.06 \%$ & $0.80 \%$ & $0.02 \%$ \\
\hline Increasing & Mesic to Wet & $0.94 \%$ & $1.28 \%$ & $8.25 \%$ \\
NDVI & Dry to Mesic & $3.45 \%$ & $5.61 \%$ & $21.85 \%$ \\
& Dry to Wet & $0.00 \%$ & $0.00 \%$ & $0.01 \%$ \\
\hline- & No Change & $88.72 \%$ & $87.80 \%$ & $69.47 \%$ \\
\hline
\end{tabular}




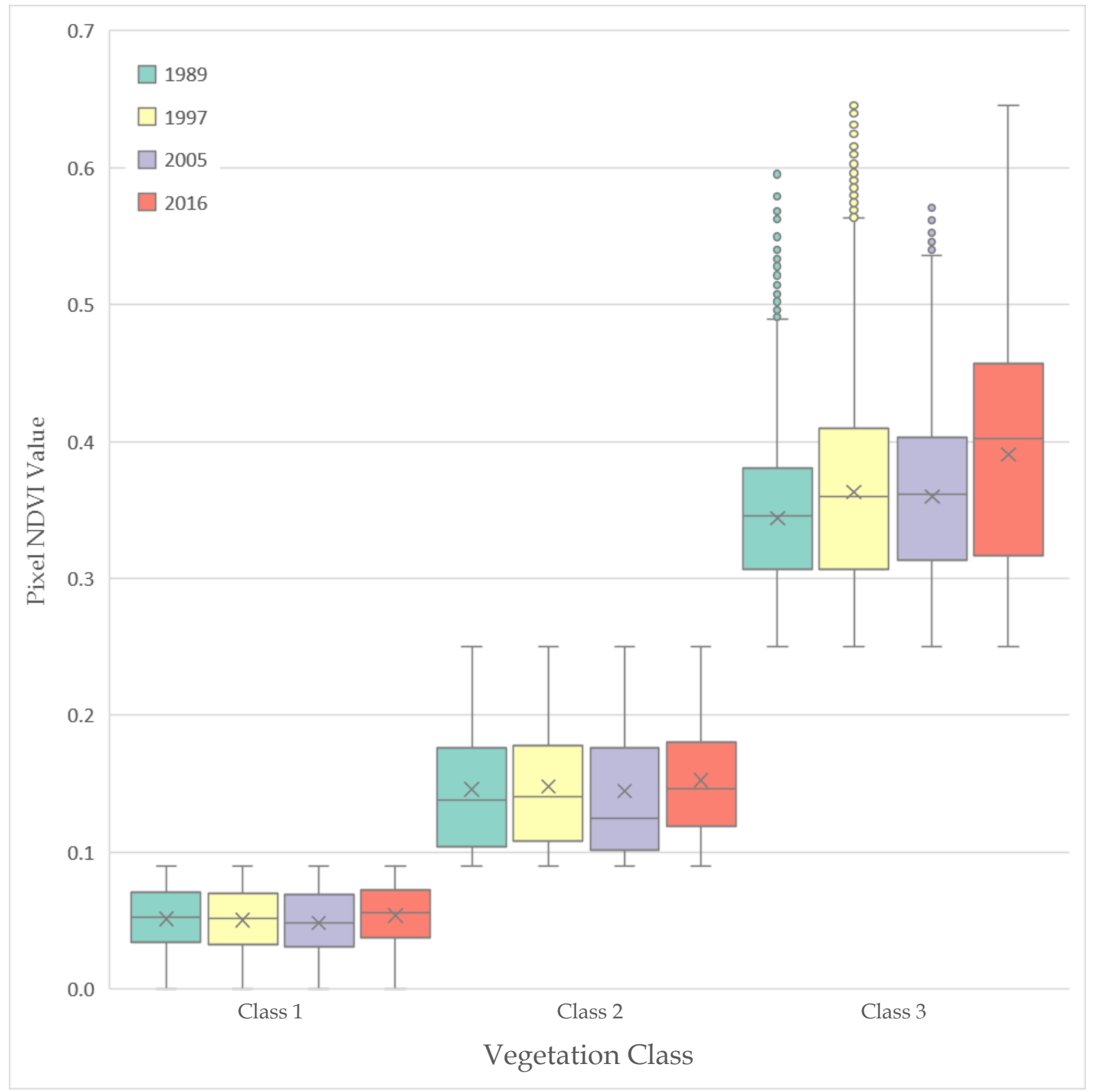

Figure 4.9: Subclass NDVI trends for the Ivvisa watershed 


\subsubsection{Salmon Creek Watershed Analysis}

The second watershed used for case study analysis was the Salmon Creek watershed (Figure 4.10). It is to the southeast of the Ivvisa watershed and is much smaller, with an area of $50 \mathrm{~km}^{2}$. It is on a slight plateau, as just past the northeast watershed border there can be seen a hillside sloping downwards into an adjacent valley. The watershed is mostly flat and featureless, with no glacial mass and a few small lakes in the northwest corner. One of those lakes (identified on the map) is the current drinking water reservoir (glacier melt fed) for the community of Pond Inlet and so a pumping station as well as a few dirt roads are included in the watershed (Indian and Northern Affairs Canada, 2010). On the southwest corner, there is an unknown geologic striation with NW/SE orientation which reflects lighter colour than the surrounding area.

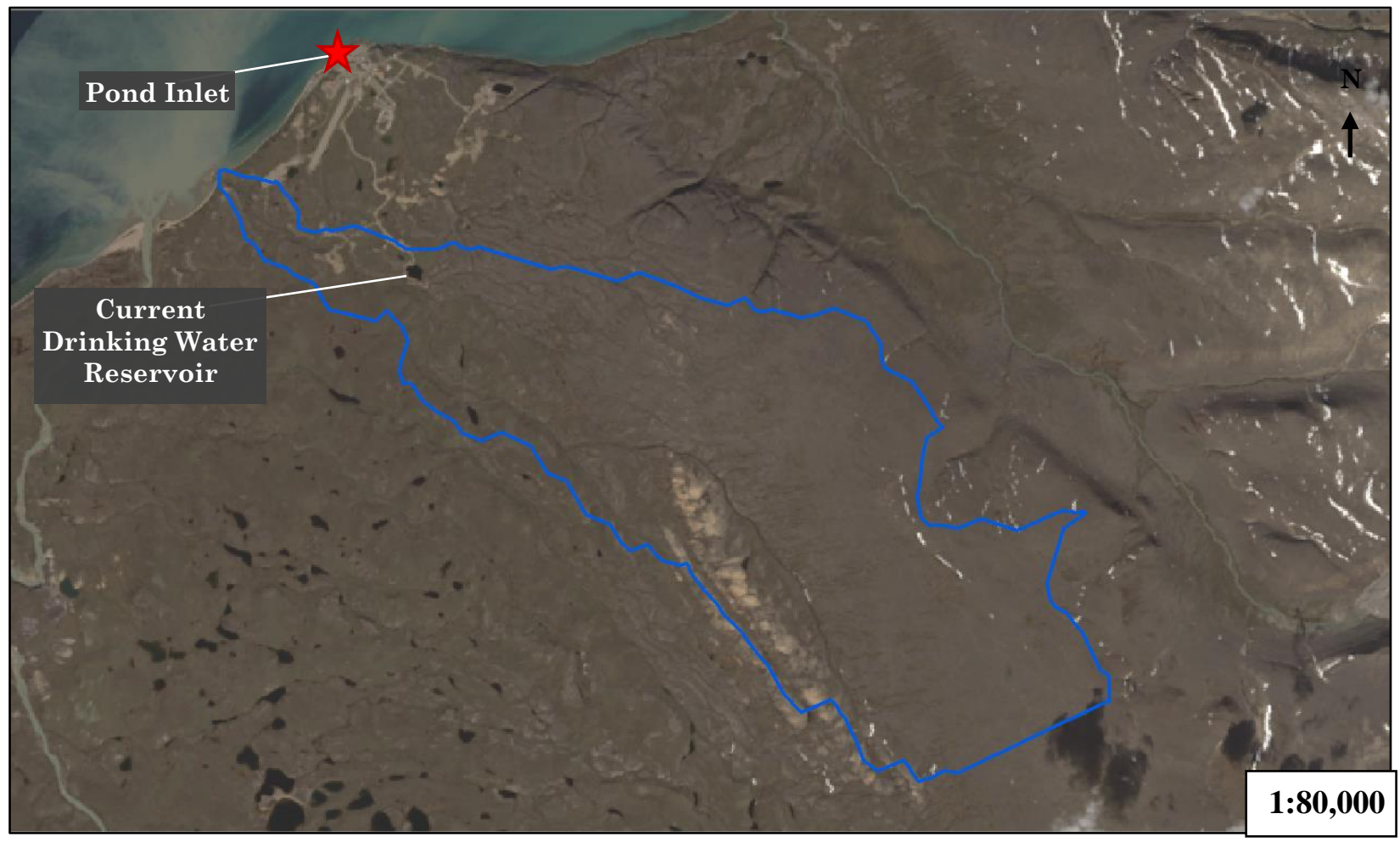

Figure 4.10: An overview of the Salmon Creek watershed (blue) displayed on the 2016 Landsat imagery.

The time series NDVI class changes can be seen in Figure 4.11. Similar to the Ivvisa watershed, there is a strong trend of spatially grouped change pixels that represent shifts between the Dry and Mesic classes. The change pixels that alternate between these two classes are located on the eastern half of the watershed in a $\mathrm{N} / \mathrm{S}$ orientation. There is also a trend of change pixels running N/S on the western half of the watershed which switch between Mesic and Wet classes. Although it is not easily discernable from the Landsat image, these spatial trends indicate that the plain gently slopes to the southwest, as there a higher proportion of vegetation communities that require moisture in the southwest half. Overall there is a higher concentration 
of change pixels in the eastern and southern sections of this watershed, compared to the northwestern tip which has areas of consistent No Change.

Similar to the Ivvisa watershed, the first two time periods show minimal $(<5.8 \%)$ change between class percentages, and the mean pixel values stay relatively consistent (Table 4.9). There is however, $14 \%$ - 15\% vegetation class change within the watershed for the first two time periods. This leads to the conclusion that if the class proportions are remaining consistent- there must be a relatively similar amount of pixels moving between the same classes. The first time period shows a slight trend towards decreasing NDVI classes (Mesic to Dry), whereas the second time period has a slight increasing trend (Dry to Mesic). The third time period however had a substantial increase in the amount of change (29\% change pixels), with over $99 \%$ of that change resulting in increasing NDVI trends. Unlike the Ivvisa watershed, the changes moving from the Mesic to Wet classes are much higher than the Dry to Mesic class changes. These differences could be due to the previously mentioned downsloping of the lower west side of the watershed which would gather moisture and promote plant biomass (Stow et al., 2004). Figure 4.11 shows a strong concentration of the Mesic to Wet change pixels oriented from north to south along the west border, extending to the central watershed area but not present on the elevated eastern side.

The box-and-whisker plot for the Salmon Creek Watershed is shown in Figure 4.12. There is a strong trend in the NDVI values of Class 1 , showing a significant clustering towards the threshold value (0.09). The location of the median near the top of the box reveals that there are a large number of pixel values grouped in the uppermost range of this class. The mean is pulled down to the center of the plot by the outliers that remain in the lower portion of this class. Compared to the Ivvisa watershed, this indicates that in general, this watershed contains fewer areas of bare/little vegetation. Class 2 shows a very similar pixel distribution from 1989 to 2005, where the median is lower than the mean and the lower whiskers are much shorter than the upper whiskers. This reveals that there is a concentration of NDVI pixel values in the lower end of this class, making the first quartile compact. This confirms the earlier suggestions that pixels are clustering around the 0.09 threshold point so exaggerated change is occurring between these classes - also congruent with the findings in the Ivvisa watershed.

The 2016 values for Class 2 show a separate trend, where pixels values are more normally distributed and not overly skewed in any particular direction. The Class 3 values for 2016 are also more normally distributed than the other years, but show a much wider variation (by the large IQRs), and a modest skew to higher values. Compared to the Class 3 values from 1989 to 2005, the pixel values in 2016 are much higher overall. Table 4.9 shows that the mean NDVI increased from 0.181 to 0.189 to 0.252 over the three time periods. The even spread of the IQRs along with the similar mean to median values suggest that shifts into this class are not as congregated around the threshold as between Class 1 and 2 . The variability of pixel 
values in Class 3 can be seen to increase throughout the years as the IQRs expand. The upper whiskers also progressively extend, showing an increase in the majority of pixel values. This means that pixel vaues tend to collect in the lower range (0.3-0.4) of Class 3, but are not clustered around the threshold point (0.25). Greening trends present in the watershed can be explained in part by the increasing mean of Class 3 , as well as the increasing variability over the time series.

To summarize the findings of the statistical analysis of the Salmon Creek watershed, there is a significant clustering of pixel values at the threshold border of Class 1 and 2, likely resulting in excessive changes being identified between the Dry and Mesic classes. The pixel statistics for Class 3 show that there is a trend of increasing variability with time, as well as a significant increase in NDVI within the 2016 image. The pixel distributions in Class 3 are skewed by some outlying higher NDVI values, which indicates that there are small areas of particularly high vegetation in the watershed. The Class 3 data for all years does not show an overly strong clustering towards the 0.25 threshold, indicating that class change between the Mesic and Wet classes is significant. 
Table 4.9: Watershed NDVI properties for the Salmon Creek Watershed

\begin{tabular}{ccccc}
\hline \hline Year & Mean (Standard Dev) & Pixels in Class 1 & Pixels in Class 2 & Pixels in Class 3 \\
& & $0-0.095$ & $0.095-0.25$ & $0.25-0.1$ \\
\hline 1989 & $0.185(0.092)$ & $10.50 \%$ & $63.43 \%$ & $26.07 \%$ \\
1997 & $0.181(0.092)$ & $13.34 \%$ & $61.92 \%$ & $24.75 \%$ \\
2005 & $0.189(0.101)$ & $15.17 \%$ & $57.61 \%$ & $27.22 \%$ \\
2016 & $0.252(0.108)$ & $0.78 \%$ & $57.12 \%$ & $42.09 \%$ \\
\hline
\end{tabular}

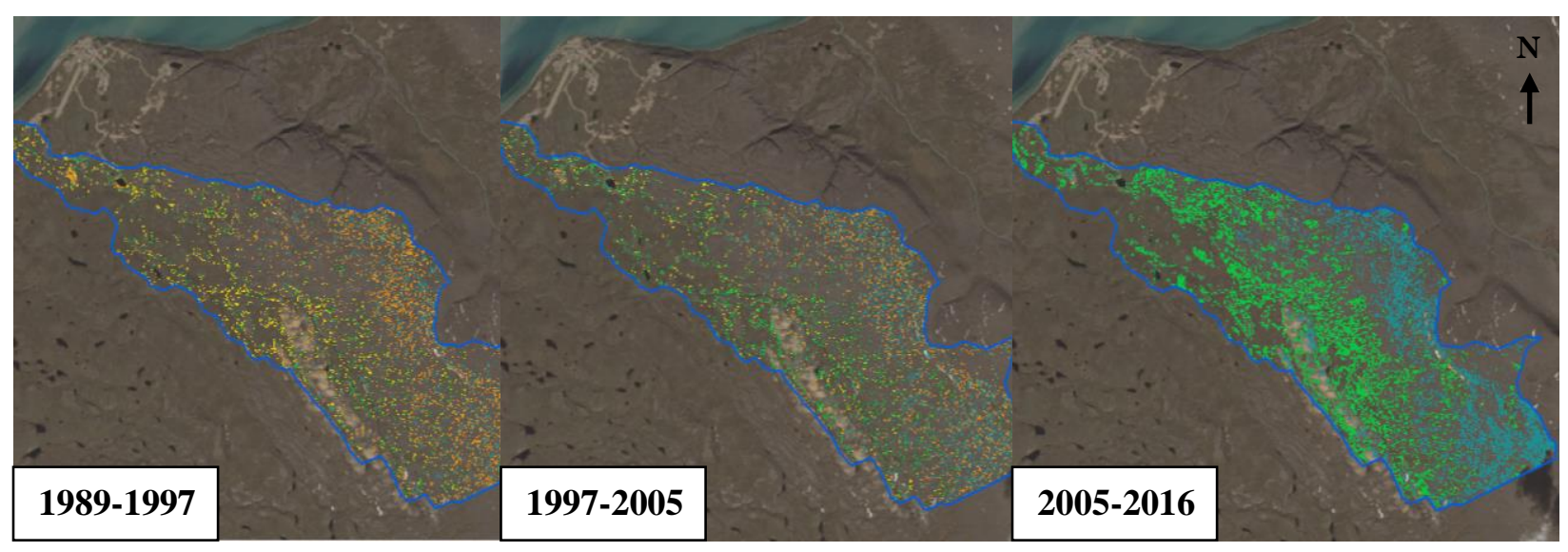

Figure 4.11: Time series trends in vegetation classes for the Salmon Creek watershed. Red/orange hues are time shifts towards decreasing NDVI classes, green/blue hues are shifts towards increasing NDVI classes.

Table 4.10: Pixel Change distribution within classes for the Salmon Creek Watershed

\begin{tabular}{ccccc}
\hline \hline & Class Change & $\begin{array}{c}\text { Percent Change for } \\
\mathbf{1 9 8 9 - 1 9 9 7}\end{array}$ & $\begin{array}{c}\text { Percent Change for } \\
\mathbf{1 9 9 7 - 2 0 0 5}\end{array}$ & $\begin{array}{c}\text { Percent Change for } \\
\mathbf{2 0 0 5 - 2 0 1 6}\end{array}$ \\
\hline Decreasing & Wet to Dry & $0.00 \%$ & $0.00 \%$ & $0.00 \%$ \\
NDVI & Mesic to Dry & $6.19 \%$ & $4.43 \%$ & $0.12 \%$ \\
& Wet to Mesic & $3.04 \%$ & $1.27 \%$ & $0.04 \%$ \\
\hline Increasing & Mesic to Wet & $1.65 \%$ & $3.75 \%$ & $17.00 \%$ \\
NDVI & Dry to Mesic & $3.02 \%$ & $5.41 \%$ & $11.91 \%$ \\
& Dry to Wet & $0.00 \%$ & $0.00 \%$ & $0.00 \%$ \\
\hline- & No Change & $86.09 \%$ & $85.14 \%$ & $70.93 \%$ \\
\hline
\end{tabular}




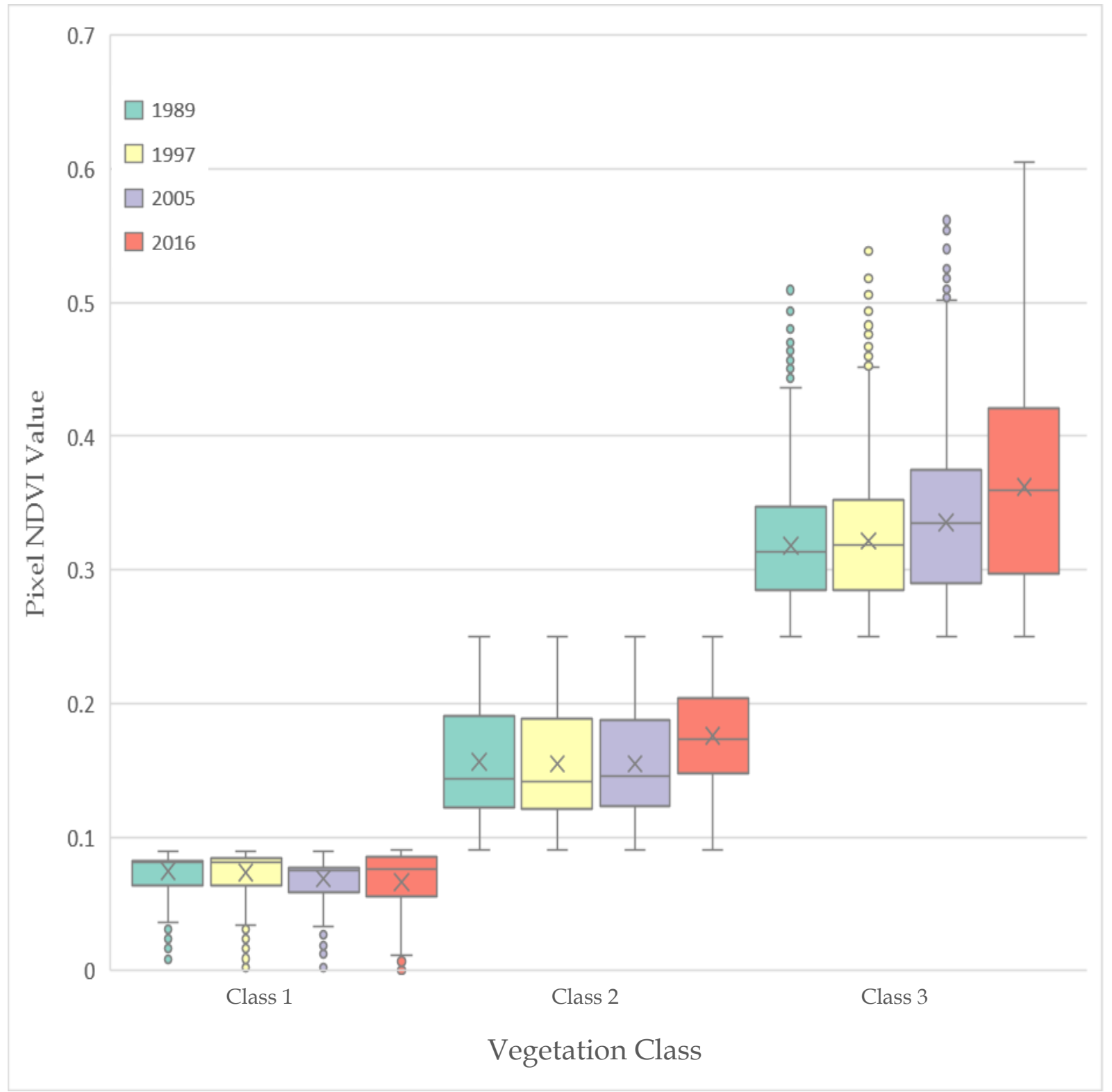

Figure 4.12: Subclass NDVI trends for the Salmon Creek Watershed. 


\subsubsection{New Water Lake Watershed Analysis}

The third and final watershed is the New Water Lake watershed (Figure 4.13). It is the furthest south of the three watersheds and the smallest with an area of $17 \mathrm{~km}^{2}$. Topography appears to be relatively flat and at a low elevation. There are no glaciers located inside the watershed and it is largely featureless, other than the few scattered lakes and stream courses connecting them. One of these lakes (marked on map) is under consideration to be a new drinking water source. The watershed empties into a major river before it is carried out into the Arctic Ocean. Outside the watershed to the southwest can be seen a large area with numerous lakes and kettle holes.

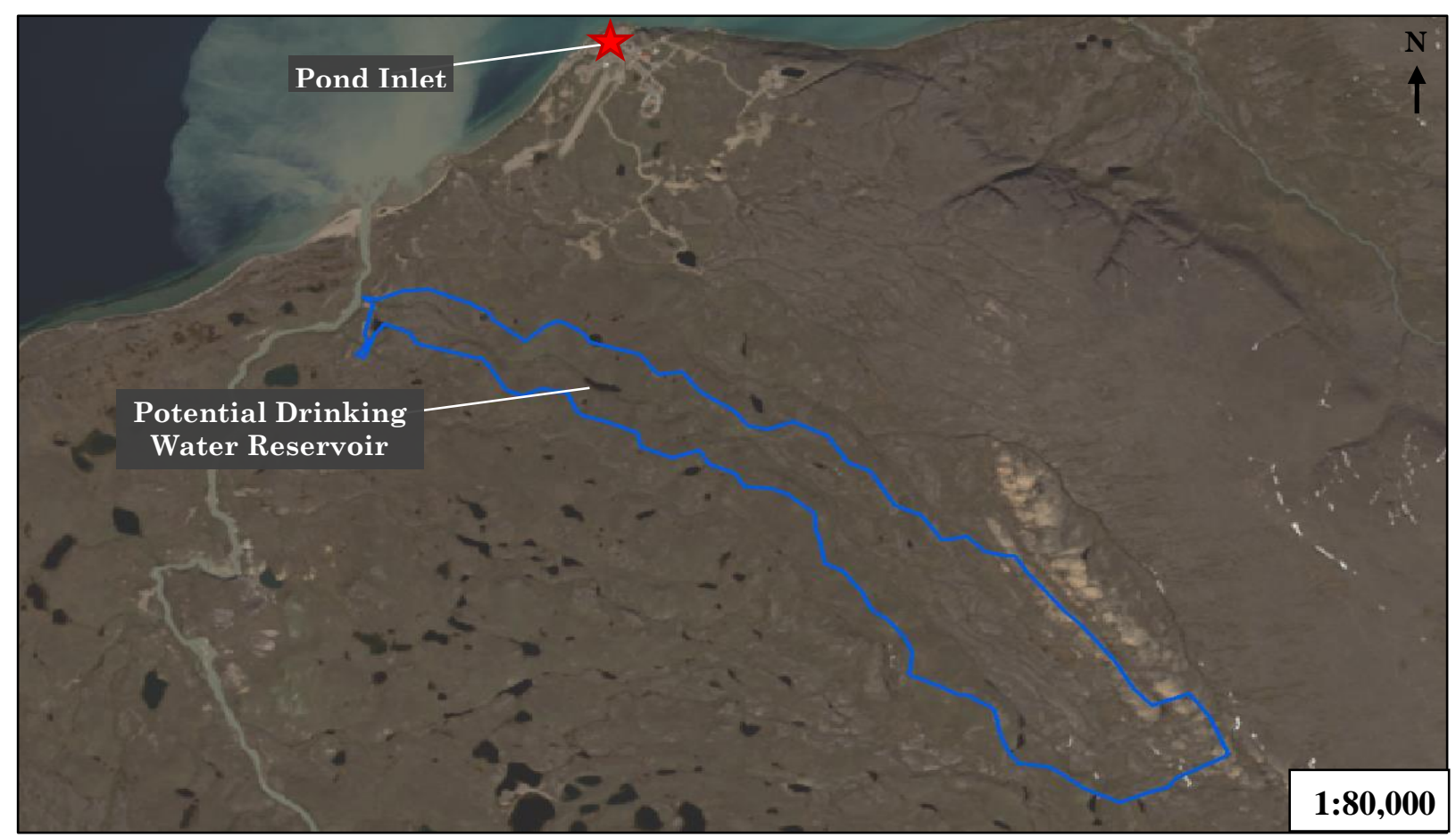

Figure 4.13: An overview of the New Water Lake watershed (blue) displayed on the 2016 Landsat imagery.

Although elevation is not entirely discernable from the Landsat image, it is presumed that this watershed must be a low lying area from the class distribution shown in Table 4.11. For all years in the time series, there is less than $3 \%$ of pixels classified into the Dry class, indicating this is a continuously high vegetation and moisture area, as high biomass in the Arctic correlates to high moisture content (Stow et al., 2004). Therefore, the majority of pixels are in Class 2 and 3, and as such, most of the change in Figure 4.14 reflects class shifts between these two classes. The initial time period image has relatively few change pixels $(<8 \%)$, but out of that change $75 \%$ was decreasing from Wet to Mesic classes. This is consistent with the overall trend across the three watersheds for the initial time period to be a period of reductions in NDVI. Also consistent with the other watershed trends, the second time period shows a shift towards NDVI class increases, where about $70 \%$ of change pixels move from the Mesic to Wet class. Figure 4.14 supports this 
as many of the areas of change move from yellow to green in the two time periods. By the third time period there is a spatial trend that can be seen whereby change pixels concentrate in the broad southern region of the watershed, and in a small area in the northwestern corner. Little change occurs in the thinner section inbetween. The final time period image shows a strong shift towards increasing NDVI classes. Out of the $19 \%$ change occurring in the final time period image, there are almost no pixels $(<1 \%)$ that move down a class, $13 \%$ of that change that moves from Dry to Mesic, and $76 \%$ that shift from the Mesic to Wet classes.

Similar to the previous watershed analysis, the percentage of pixels in each class does not vary much from 1989 to 2005 . However, the setting of this watershed is no longer moisture-deficient, hence why there are almost no Dry vegetation pixels. This means that the change that was occurring in the first two time periods between the lower NDVI classes is no longer likely. Instead, the change occurring from 1989 to 2005 is a product of shifts within the highest classes (Mesic and Wet). If the class percentages remain the same, yet there is still change, it is likely due to a legitimate shift in vegetation between the two highest classes. By using the box-and-whisker plots it is possible to tell if the transfer between the Mesic and Wet classes are because of pixel clustering or because of fluctuating vegetation conditions.

The box-and-whisker plot shown in Figure 4.15 indicates that the subclass distributions of both the Mesic and Wet vegetation classes are normal. The mean values align closely with the median values in all but the 2016 Class 3 group. The IQRs are generally even, with only a slight group shift towards higher NDVI values for Class 2, shown by the somewhat shorter upper whisker. The Class 3 values begin to subtly increase in variance and spread, and as expected from other watersheds, the 2016 NDVI values show a significant increase. Although all of the Class 3 groups show a right skew (to higher values), there is no apparent clustering at the 0.25 threshold since the IQR and median/mean lines are all normal. The Class 1 pixel values show very high variance with small ranges for all years, which is expected as the sample of pixels in these classes is very low. There is significant clustering of values towards the 0.09 threshold, indicating that the few pixels in these classes could likely be easily transferred into Class 2 with minute spectral differences.

To summarize the findings of the statistical analysis of the New Water Lake watershed, there is a continued trend from other watersheds of good class separability between the Mesic and Wet classes. This means that the NDVI values of each class have somewhat normal distribution and the high degree of change between the Mesic and Wet classes is likely a result of legitimate vegetation shifts. The pixel distribution in Class 1 however are skewed and clustered too close to the Class 2 threshold to represent meaningful change. 
Table 4.11: Watershed level NDSI Properties for the New Water Lake Watershed

\begin{tabular}{ccccc}
\hline \hline Year & Mean (Standard Dev) & Pixels in Class 1 & Pixels in Class 2 & Pixels in Class 3 \\
& & $0-0.095$ & $0.095-0.25$ & $0.25-0.1$ \\
\hline 1989 & $0.279(0.0850)$ & $1.95 \%$ & $31.60 \%$ & $66.45 \%$ \\
1997 & $0.273(0.089)$ & $2.28 \%$ & $33.41 \%$ & $64.31 \%$ \\
2005 & $0.290(0.099)$ & $2.66 \%$ & $30.46 \%$ & $66.89 \%$ \\
2016 & $0.362(0.103)$ & $0.39 \%$ & $16.35 \%$ & $83.26 \%$ \\
\hline
\end{tabular}

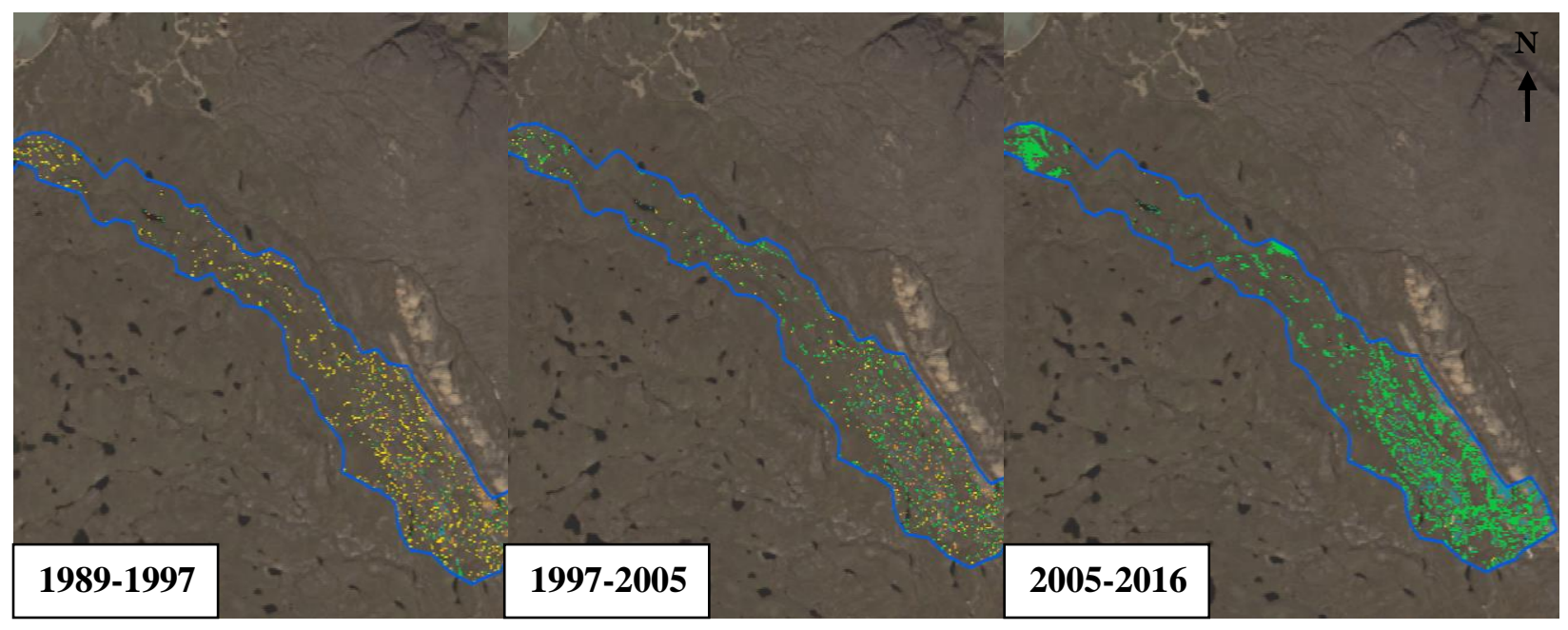

Figure 4.14: Time series trends in vegetation classes for the New Water Lake watershed. Red/orange hues are time shifts towards decreasing NDVI classes, green/blue hues are shifts towards increasing NDVI classes.

Table 4.12:Pixel Change distribution within classes for the New Water Lake Watershed

\begin{tabular}{ccccc}
\hline \hline & Class Change & $\begin{array}{c}\text { Percent Change for } \\
\mathbf{1 9 8 9 - 1 9 9 7}\end{array}$ & $\begin{array}{c}\text { Percent Change for } \\
\mathbf{1 9 9 7 - 2 0 0 5}\end{array}$ & $\begin{array}{c}\text { Percent Change for } \\
\mathbf{2 0 0 5 - 2 0 1 6}\end{array}$ \\
\hline Decreasing & Wet to Dry & $0.00 \%$ & $0.00 \%$ & $0.00 \%$ \\
NDVI & Mesic to Dry & $1.08 \%$ & $0.92 \%$ & $0.05 \%$ \\
& Wet to Mesic & $4.81 \%$ & $1.50 \%$ & $0.08 \%$ \\
\hline Increasing & Mesic to Wet & $1.47 \%$ & $4.84 \%$ & $16.15 \%$ \\
NDVI & Dry to Mesic & $0.41 \%$ & $0.73 \%$ & $2.51 \%$ \\
& Dry to Wet & $0.01 \%$ & $0.00 \%$ & $0.01 \%$ \\
\hline-0 & No Change & $92.22 \%$ & $92.01 \%$ & $81.20 \%$ \\
\hline
\end{tabular}




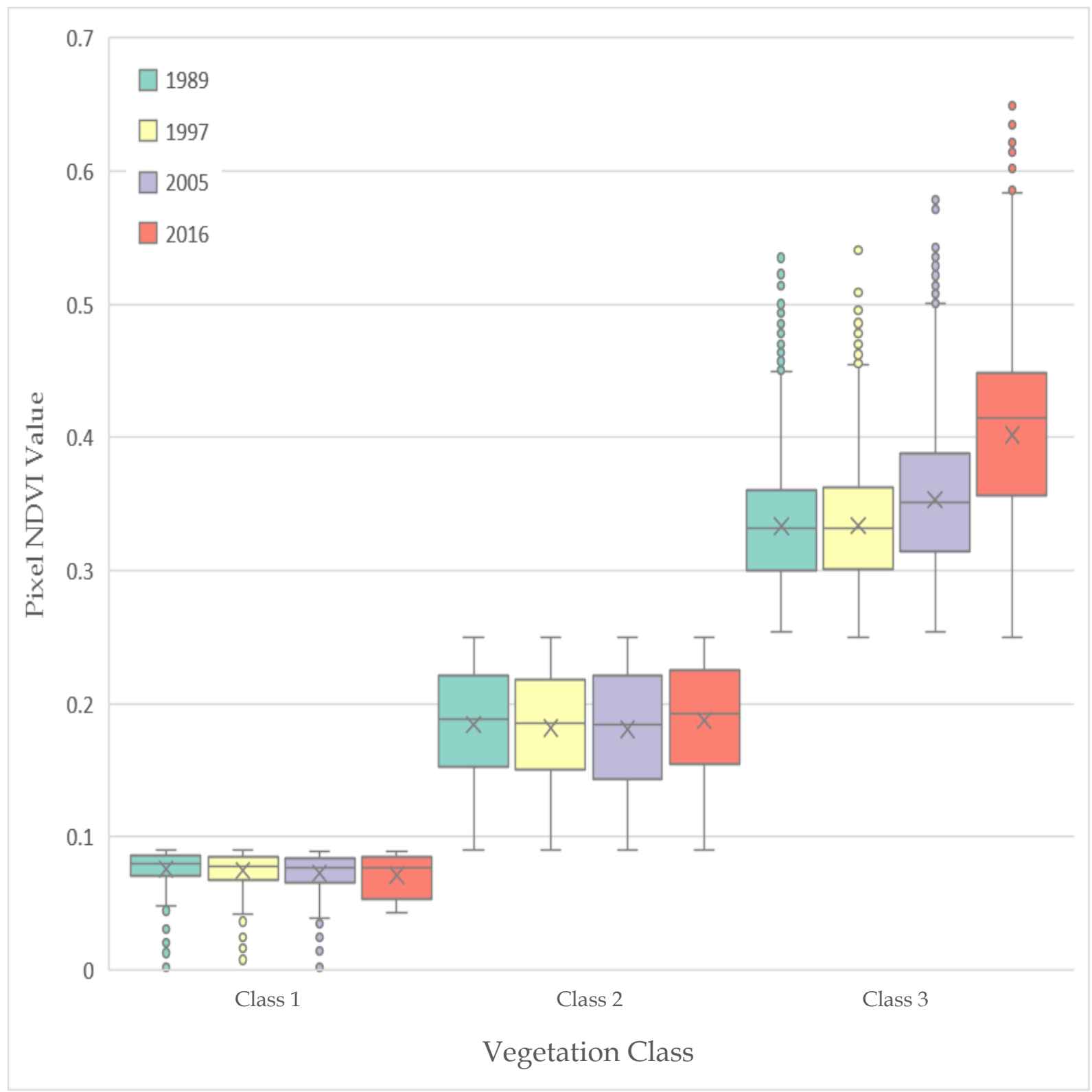

Figure 4.15: Subclass NDVI trends for the New Water Lake Watershed. 


\subsection{Discussion}

The results of glacial change over the time series from Section 4.1 indicate a strong trend towards increasing mass loss. Specifically, the area of loss grows from $26 \mathrm{~km}^{2}$ to $161 \mathrm{~km}^{2}$ to $376 \mathrm{~km}^{2}$ through each consecutive time period. This equals a yearly rate of melt $0.124 \%, 0.716 \%$, and $1.33 \%$ through each consecutive time period. This finding is consistent and well documented in many other studies on Arctic glaciers, all of which note an intensifying trend of melt in the last decade (Gardner et al., 2012; Sharp et al., 2011; Vincent et al., 2011; Way, 2014). In the Queen Elizabeth Islands, Nunavut, Sharp et al. (2011) report that glaciers monitored since 1963 have had an overall trend of ice loss, with a notable increase after 2005. Out of the total mass lost, 30-48\% occurred from 2005 to 2009 (7.5-12\% per year), whereas the results of this MRP found that $67 \%$ of the total loss occurred from 2005 to 2016 (6\% loss per year). Likewise, a study by Gardner et al. (2012) reports that historical melt rates (since 1963) on Baffin and Bylot Islands have doubled since 2003. The results from Section 4.1 support this study, as although the study periods are not the same, there is definitely an increase in the rate of loss after 2005. The average rate of loss from 1989-2005 is $0.42 \%$ per year, which then increases over threefold to the $2005-2016$ loss rate of $1.33 \%$ per year. Some comparisons between glacial loss studies is difficult due to the fact that many studies report loss in terms of volume. Differences in values between reports could be the combination of time period differences, study area size, microclimate variability, also higher methodological power with increased data coverage and elevation models. However, the vast body of literature notes a trend of increasing glacial loss across the Arctic, specifically in the last decade. This is MRP shows that this trend has also manifested itself at the local level of Pond Inlet.

Many of these studies identify increasing temperature trends as the likely culprit inducing change. Gardner et al. (2012), determined that 70-98\% of the variance of melt rate increases are due to changes in summer temperatures. Sharp et al. (2012) are more general, and suggest an association of melt rates to the atmospheric circulation of heat rising from warm sea water. The coastal location of Pond Inlet may be influenced by ocean water that promotes melt, especially for the many sections of snowpack along the coast. Increasing air temperatures have been accelerating since 1980, and have risen most dramatically since 2005 (Overland et al., 2016). This supports the increasing trend of mass loss from 1989-2016, as well as the stark jump in melt area seen in the last time period. Figure 4.16 below shows a graph of the Pond Inlet climate differentials to the 1976-1996 average. The increase in melt rate resembles the increase in temperature that has been recorded on this graph. There is also no significant trend for winter snowfall, meaning that little change in snowpack accumulation has occurred to balance the high rates of loss. 


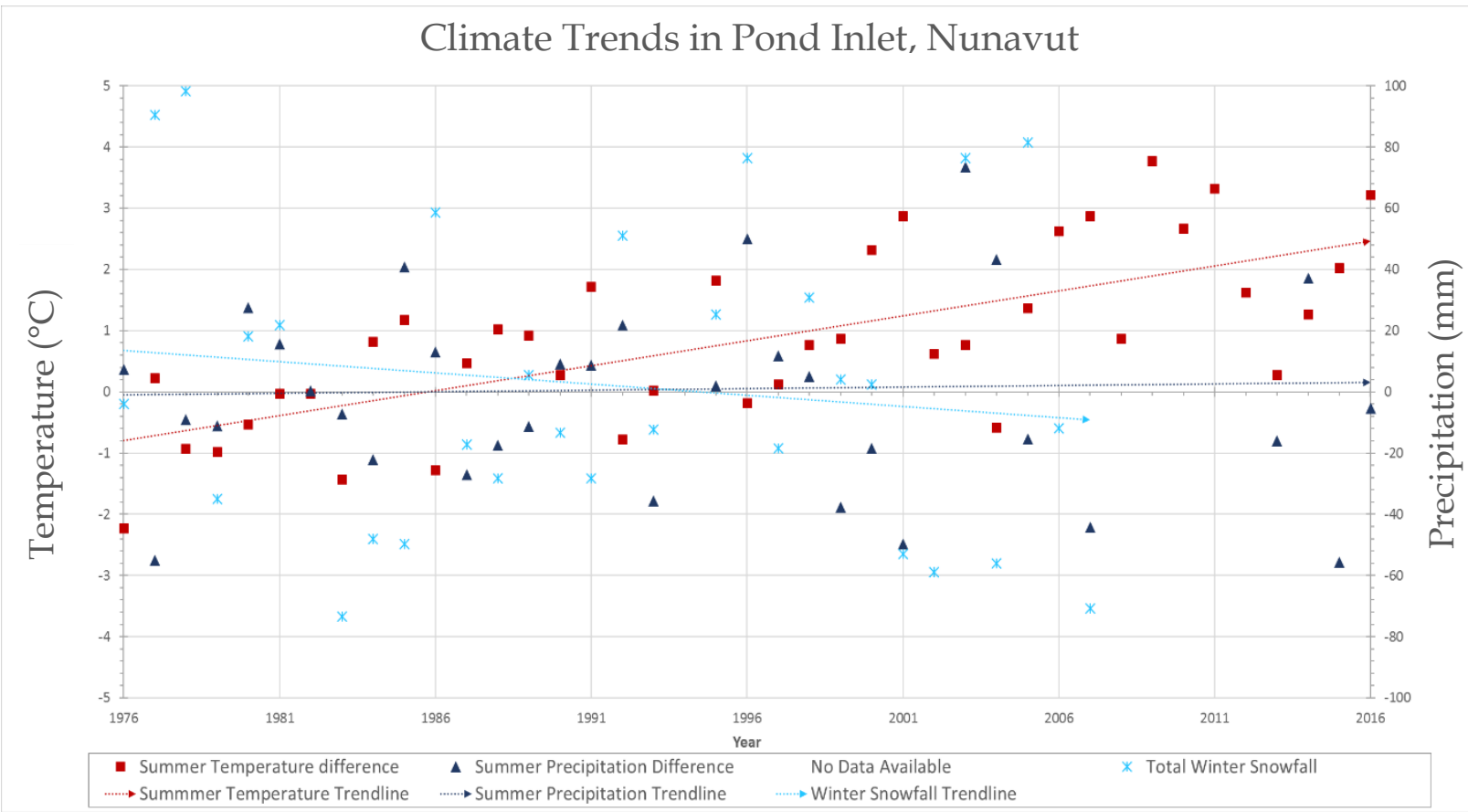

Figure 4.16: Climate trends for Pond Inlet, recorded at the Environment Canada weather station at Pond Inlet Airport (GOC, 2016). Red markers indicate the degree of temperature above the 20 year average from 1976-1996. Blue markers represent the amount of rain above the 20 year average from 1976-1996. Flat grey markers represent years with no data. Dotted vertical lines mark the image years used in this study.

The results of the analysis to detect vegetation shifts that occurred over the time series are split up into two levels: the entire study area (global level), and watershed area (local level). In the analysis looking at global trends, there is a consistent decrease in NDVI class from 1989 to 1997. This is mostly expressed as shifts from the Mesic to Dry vegetation class, with smaller shifts from the Wet to Mesic class. In 1997 to 2005, this change remains consistent in extent and magnitude, but reverses direction and reveals increasing NDVI trends. Change occurs predominantly in areas moving from the Dry to Mesic vegetation class, with smaller shifts from the Mesic to Wet class. In the final time period from 2005 to 2016, there is a substantial increase in both the values of NDVI as well as the area of change. This is consistent with relevant Arctic literature which reports a significant increase in biomass in the last decade (Epstein et al., 2012; Olthof et al., 2008; Raynolds \& Walker, 2016).

The findings observed at the global level are also shown at the local level of vegetation analysis. However, the local (watershed) level of analysis does not validate the magnitude of shifts occurring between the Dry and Mesic classes. This is due to the findings from the case study analysis at the subclass level, in which a clustering of pixel values around the Dry/Mesic threshold leads to a higher sensitivity of pixel movement; inflating the amount change. This should not call into question the fact that the NDVI values are indeed changing when they cross the 0.09 threshold, however, it indicates that shifts across this threshold may not be representative of an entire community movement. The local level of analysis does support the global 
findings that change between Mesic and Wet vegetation classes is significant, as there is suitable normality between groups. The significant change between Mesic and Wet classes, especially in the latter years is echoed in many other studies. Arctic research by Jia et al. (2003) confirm that the greatest changes in NDVI values occur in the moist, graminoid (Mesic/Wet) communities. Olthof et al. (2008), also confirm that Wet type ecosystems have the highest annual NDVI increases, whereas drier, lichen based communities show a dampened increase.

Bhatt et al. (2010) report an increase of $~ 15 \%$ max NDVI in northern Baffin Island from 1982 - 2008, and correlate these changes Arctic tundra vegetation to temperature. Ground level photographs of their study site (not far from Pond Inlet) show a thickening of vegetation in the tundra valley from 1963 to 2009. Similarly, Epstein et al. (2012), report an average biomass increase of $19.8 \%$ in the Arctic tundra from 1982-2010, which was supported with field measurements of biomass. This also is comparable to the findings of Jia et al. in 2009, who calculated an average yearly increase of 0.46-0.67\% from 1982-2006 in the low Arctic. This percentage matches the average yearly average increase of $0.42 \%$ found in this MRP, from 1989-2005. From the results of Neigh et al. (2008), the causes of biomass change in northern latitudes where anthropogenic land use is not apparent are both long-term climate change and decadal variability. As seen in the temperature graphs of Figure 1.1 and 4.16, there has been a notable increase of temperature, particularly in the last decade which could be fueling this increasing NDVI trend in Pond Inlet.

Numerous studies in the Arctic report that increasing NDVI trends have been occurring over the past several decades (Epstein et al., 2012; Jia \& Epstein, 2003; Olthof et al., 2008). The results of this analysis do not show an increase in the first time period, but there is an increasing trend overall. This fluctuation in the first time period is also noted by Zhou et al. (2001), who report the changes across North America to be more heterogeneous. This could be due to climate change factors like reduced vegetation from the drying up of small wetlands and permafrost wedges (Perreault et al., 2017). Although, it is more likely due to the colder than average temperatures for 1997, resulting in a delayed melt season and delayed peak phenology period (Figure 1.1). This peak growth suppression is supported by the findings in Jia et al. (2003), who report that decreases in NDVI correspond to colder summer temperatures. Similarly, Høgda et al. (2013) found the start of the growing season is strongly dependent on warmer temperatures. This growing season phenomenon may have also influenced the statistics for the other three years as the average max summer temperature values for all years are above the 1976-1996 average (Figure 4.16). There is a strong trend towards increasing temperatures after 1997, shown in Figure 4.16, where both 2005 and 2016 are well above the 1976-1996 mean. Many studies, such as Woo and Young (2006), agree that temperature and water dependencies are the main growth limiting factors of vegetation in the Arctic tundra (Stow et al., 2004; Høye et al., 2007). Experimental plot studies have strongly correlated increased air temperature to 
increases in biomass and NDVI (Boelman et al., 2003; Edwards \& Henry, 2016). Combining temperature data with precipitation data for Pond Inlet reveals that although there have been no significant increases in total precipitation, there has been increases in temperature in the past three decades (see Figure 4.16).

\subsection{Limitations}

One of the limitations frequently discussed throughout this paper is the climatic variability between the images, particularly the colder trends of 1997. As noted by Lumbierres et al. (2017), using predefined time periods to capture comparable vegetation stages is acceptable, however problems can occur when seasonal cycles become irregular, as with the case of 1997 where typical peak vegetation is reduced. This issue was because of the lack of available satellite imagery over the study period. No year immediately before or after had suitable imagery which could be used instead. The delay in 1997 which caused low NDVI values may not have been representative of average trends, however it did show that the NDVI method is sensitive to change.

Another feature of the Landsat data used is that the minimum spatial resolution was $30 \mathrm{~m}$ by $30 \mathrm{~m}$. This means that it would not be possible to identify the changes within small or elongated wetlands that did not take up the pixel majority. The relationship between vegetation and NDVI has proved to be robust at large scales, however the nature of a remote sensing study is that much of the heterogeneity of small features is lost in pixels. Arctic vegetation is highly heterogeneous, and it is expected that climate induced modification will occur at vegetation boundaries (Silapaswan et al., 2001; Stow et al., 2004). The limitation of having such coarse resolution data is that it limits the findings of the study to more large scale change which can surpass the pixel size threshold (Lumbierres et al., 2017). The same issues apply to detecting glacial extent where glacial features may be eliminated if they do not take up the underlying land cover majority.

There are inherent issues with categorizing a continuous variable by predefined classes. This issue is revealed in the subclass analysis which shows clustering between the threshold of Class 1 and 2. This threshold clustering indicates that many pixels can switch classes with only small changes in NDVI. This limitation occurred because of the desire to quantify change into vegetation community (class) movements. However, by using categorical variables all of the sub-class changes are masked and only movement across the class thresholds is identified. 


\section{CHAPTER FIVE: CONCLUSION}

\subsection{Conclusions}

The initial goals set out for this paper were completed. Remote sensing techniques were successful in determining the extent of glacial loss over the time series, as well as capturing the vegetation shifts that occurred. Figure 5.1 illustrates these changes, revealing that there has been an increase in vegetation community disruption (i.e NDVI pixel values located in the Arctic tundra are changing classes), along with an increase in the percentage of glacial loss. The reduction of glacial extent has been increasing through the time series and significant loss is found in the last time period. Vegetation change includes an initial decrease in NDVI, but an overall NDVI increase. Subclass analysis reveals that changes between the Dry and Mesic vegetation classes, which caused the initial decreasing trend, were not altogether representative of an entire vegetation class shift, compounded by lower than average phenology trends in the 1997 image. Subsequent increases in NDVI for the final time period indicate significant 'greening', shifting vegetation communities into the Mesic and Wet classes. This observation remains valid at the subclass level.

\section{Glacial and Vegetation Change Trends in Pond Inlet, Nunavut}

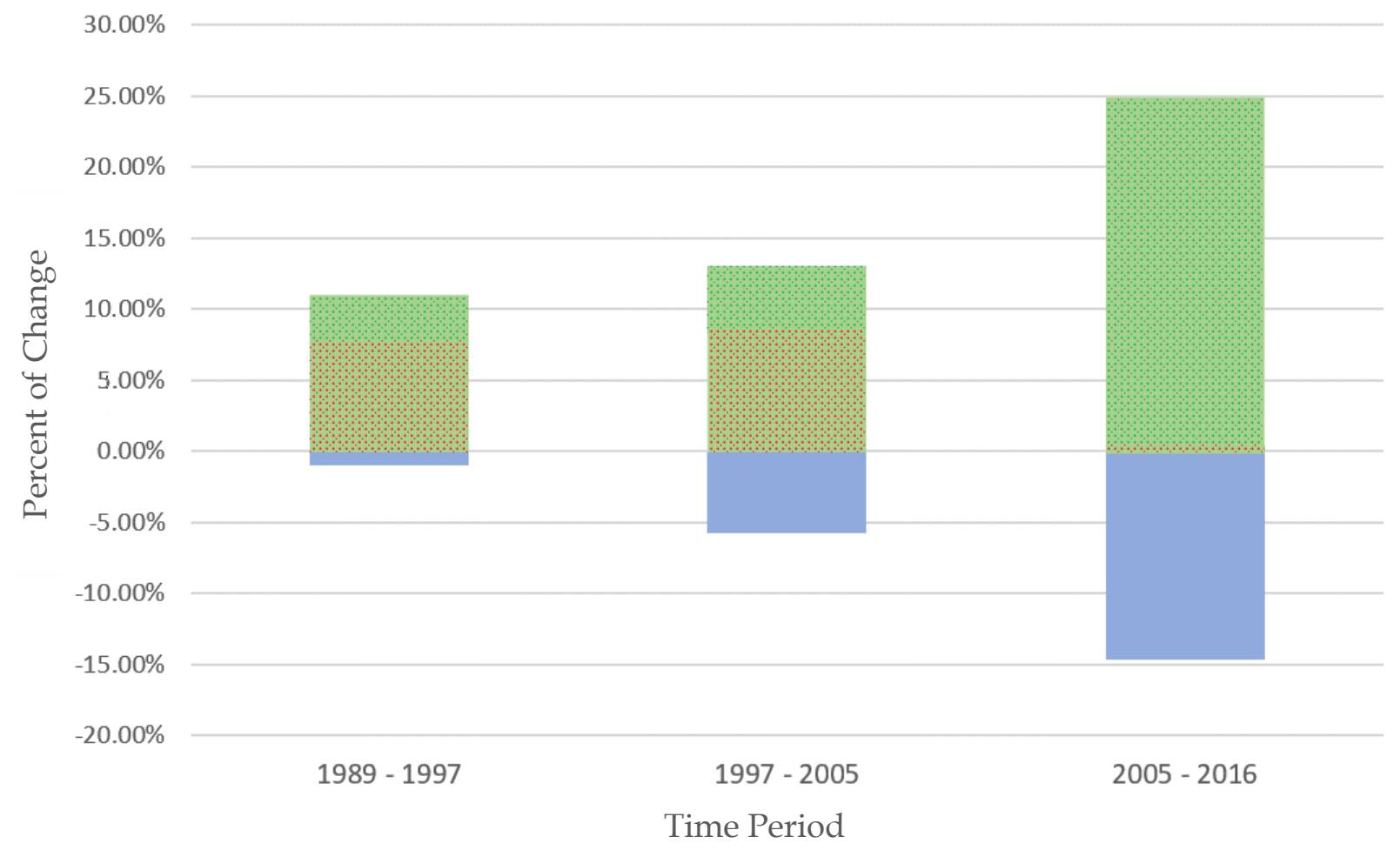

Figure 5.1: Combined vegetation and glacial change in Pond Inlet, Nunavut over the three time series. Blue bars represent percent loss of glacial features in each time period. Green speckled bars represent the area that has increased in NDVI, and red speckled bars represent the area that has decreased in NDVI. 
Many studies link these landscape changes in the Arctic to climate change and increased temperatures. The observations of higher glacial melt along with increases in mesic and wetland vegetation classes coincide with increasing temperature trends. Temperatures in Pond Inlet have risen nearly $3.5^{\circ} \mathrm{C}$ from 1976 to 2016 , with all the summer temperatures after 2005 above the historical 2-decade average (1976-1996; Figure 4.16). The significant rate of temperature increase along with the extensive amount of glacial loss and vegetation greening in the last decade are cause for concern. Continued efforts should be made to monitor these trends in the future, as the rate of change appears to be increasing. The results described above satisfy the aims of assessing climate-induced landscape change in Pond Inlet. This research also leads to further questions regarding the impacts of this landscape change, including what implications it may have on the community of Pond Inlet.

\subsection{Future Work}

While remote sensing techniques were successful in making observations about the landscape changes in Pond Inlet, validation through field measurements would strengthen the analysis. Specifically, supporting the current analysis of land cover change with field observations of NDVI and vegetation characteristics could allow for a much stronger assessment of vegetation change than the categorical NDVI method. As supported by Selkowitz and Forster (2015), despite the power of remote sensing techniques for determining glacial and landscape change, there is no true substitute for in-situ monitoring, as field measurements are 'irreplaceable indicators' that are not subject to spectral inequalities between images (via atmospheric, sensor, resolution, or other image related errors). However, the strength of remote sensing lies in the practicality of investigating inaccessible terrain (Selkowitz \& Forster, 2015). As such, this analysis should be used in complement to field studies which can further validate the landscape changes occurring.

The results of this analysis show significant ecological changes around the community of Pond Inlet. Increased glacial melt and vegetation can have wide spanning effects such as increased presence of herbivores, entrance of non-native plant species, and higher bacterial release from melting snow and organic matter (Vincent et al., 2011). This has implications on the water quality and quantity reaching the community of Pond Inlet and their drinking water source. The vegetation shifts identified in the case study analyses show that the watersheds around the small hamlet of Pond Inlet are vulnerable to change as their land cover is being modified. This should prompt further investigation around the community of Pond Inlet to assess the local resilience to effects from continuing climate change. 


\section{REFERENCES}

Aarluk Consulting Inc. (2011). Pond Inlet Integrated Community Infrastructure Sustainability Plan Vol. 2 Consultation Report. Government of Nunavut. Retrieved April 27, 2017, from http://toolkit.buildingnunavut.com/ICSP/Pond\%20Inlet/Pond\%20Inlet\%20ICISP\%20Volume\%2 02\%20Final\%20(2011-03-04).pdf

Alessa, L., Kliskey, A., Lammers, R., Arp, C., White, D., Hinzman, L., \& Busey, R. (2008). The Arctic Water Resource Vulnerability Index: An Integrated Assessment Tool For Community Resilience And Vulnerability With Respect To Freshwater. Environmental management, 42(3), 523.

Allen, Y. C., Couvillion, B. R., \& Barras, J. A. (2012). Using Multitemporal Remote Sensing Imagery and Inundation Measures to Improve Land Change Estimates in Coastal Wetlands. Estuaries and Coasts, 35, 190-200.

Andrade-Sanchez, P., Gore, M., Heun, J., Thorp, K., Carmo-Silva, A., French, A., White, J. (2014). Development and evaluation of a field-based high-throughput phenotyping platform. Functional Plant Biology, 41(1), 68-79.

Angelo, J. (2013). Dictionary of Space Technology (2 Edition (December 1, 1998) ed.). Routledge Publishing.

Arctic Monitoring and Assessment Programme (AMAP). (2011). Snow, Water, Ice and Permafrost in the Arctic (SWIPA): Climate Change and the Cryosphere. Oslo, Norway. Chapter 7.

Atkinson, D. (2013). Polar Seal- Polar Regions Spatial and Environmental Analysis Laboratory. (Department of Geography and Environmental Studies; Ryerson University) Retrieved April 30, 2017, from http://www.geography.ryerson.ca/polarseal/

Atkinson, D., \& Treitz, P. (2012). Arctic Ecological Classifications Derived from Vegetation Community and Satellite Spectral Data. Remote Sensing, 4(12), 3948-3971.

Baldeck, C. a. (2013). Estimating Vegetation Beta Diversity From Airborne Imaging Spectroscopy And Unsupervised Clustering. Remote Sensing, 5(5), 2057-2071.

Berkes, F., \& Jolly, D. (2001). Adapting to Climate Change: Social-Ecological Resilience in a Canadian Western Arctic Community. Conservation Ecology, 5(2), 18.

Bhatt, U.S., Walker, D.A., Raynolds, M.K., Comiso, J.C., Epstein, H.E., Jia, G., \& Webber, P.J. (2010). Circumpolar Arctic Tundra Vegetation Change Is Linked to Sea Ice Decline. Earth Interactions, 14(8), 1-21.

Bruzzone, L., \& Smits, P. (2002). Analysis of Multi-Temporal Remote Sensing Images; Volume 2. Singapore: World Scientific Publishing Co.

Burkett, V., \& Kusler, J. (2000). Climate Change: Potential Impacts and Interactions in Wetlands of The United States. Journal of the American Water Resources Association, 36(2), 313-320.

Burns, P., \& Nolin, A. (2014). Using Atmospherically-Corrected Landsat Imagery To Measure Glacier Area Change In The Cordillera Blanca, Peru From 1987 to 2010. Remote Sensing of Environment, 140, 165-178. 
Cui, X., Gibbes, C., Southworth, J., \& Waylen, P. (2013). Using Remote Sensing to Quantify Vegetation Change and Ecological Resilience in a Semi-Arid System . Land(2), 108-130.

De Jong, S. M. (1994). Derivation Of Vegetative Variables From A Landsat TM Image For Modelling Soil Erosion. Earth Surface Processes and Landforms, 19(2), 165-178.

Dietz, A. J., Kuenzer, C., Gessner, U., \& Dech, S. (2012). Remote Sensing Of Snow - A Review Of Available Methods. International Journal of Remote Sensing, 33(13), 4094-4134.

Downing, A., \& Cuerrier, A. (2011). A Synthesis Of The Impacts Of Climate Change On The First Nations And Inuit Of Canada. Indian Journal of Traditional Knowledge, 10(1), 57-70.

Dozier, J. (1989). Spectral signature of alpine snow cover from the Landsat Thematic Mapper. Remote Sensing of the Environment, 28, 9-22.

Edwards, M., \& Henry, G. H. (2016). The effects of long-term experimental warming on the structure of three High Arctic plant communities. Journal of Vegetation Science, 27(5), 904-913.

Epstein, H. E., Raynolds, M. K., Walker, D. A., Bhatt, U. S., Tucker, C. J., \& Pinzon, J. E. (2012). Dynamics of aboveground phytomass of the circumpolar Arctic tundra during the past three decades. Environmental Research Letters, 7(1).

Flood, N. (2014). Continuity of Reflectance Data between Landsat-7 ETM+ and Landsat-8 OLI, for both top-of-atmosphere and surface reflectance: A Study in the Australian landscape. Remote Sensing, 6(9), 7952-7970.

Fraser, R., Olthof, I., Deschamps, A., Carrière, M., \& Pouliot, D. (2008). Detecting Vegetation Changes in Tundra using 25-year Landsat Image Stacks. Natural Resource Canada, Canada Centre for Remote Sensing. Retrieved April 21, 2017, from https://alaska.usgs.gov/science/ geography/CRSS2010/presentations/fraser_detecting_vegetation_changes_using_landsat.pdf

Gardner, A., Moholdt, G., Arendt, A., \& Wouters, B. (2012). Accelerated contributions of Canada's Baffin and Bylot Island glaciers to sea level rise over the past half century. The Cryosphere, 6 , 1103-1125.

Google Maps Imagery; DigitalGlobe, Landsat/Copernicus, IBCAO. (2017). Pond Inlet, Nunavut. Retrieved April 15, 2017, from https://www.google.ca/maps/

Government of Canada (GOC); Environment Canada. (2016). Histoical Data; Pond Inlet A. Retrieved April 20, 2017, from http://climate.weather.gc.ca/historical_data/search_historic_data_e.html

Hall, D. K., Foster, J. L., Verbyla, D. L., Klein, A. G., \& Benson, C. S. (1998). Assessment of SnowCover Mapping Accuracy in a Variety of Vegetation-Cover Densities in Central Alaska . Remote Sensing of the Environment, 66, 129-137.

Hartmann, D.L., Klein, A.M.G., Tank, M., Rusticucci, L.V., Alexander, S., Brönnimann, Y., Charabi, F.J., Dentener, E.J., Dlugokencky, D.R., Easterling, A., Kaplan, B.J., Soden, P.W., Thorne, M., Wild, P.M., \& Zhai. (2013). Contribution of Working Group I to the Fifth Assessment Report of the Intergovernmental Panel on Climate Change (Chapter 2). Cambridge University Press, Cambridge, United Kingdom and New York, NY, USA. 
Høgda, K. A., Tømmervik, H., \& Karlsen, S. R. (2013). Trends in the Start of the Growing Season in Fennoscandia 1982-2011. Remote Sensing, 5(9), 4304-4318.

Høye, T.T., Post E., Meltofte, H., Schmidt, N.M., \& Forchhammer, M.C. (2007). Rapid Advancement of Spring in the High Arctic. Current Biology. 17(12), 207-212.

Houghton, J. T., Ding, Y., Griggs, D. J., Noguer, M., van der Linden, P. J., Dai, X., \& Johnson, C. A. (2001). Climate Change 2001: Intergovernmental Panel On Climate Change . New York: Cambridge University Press.

Huck, P., Light, B., Eicken, H., \& Haller, M. (2007). Mapping sediment-laden sea ice in the Arctic using AVHRR remote-sensing data: Atmospheric correction and determination of reflectances as a function of ice type and sediment load. Remote Sensing of Environment, 107(3), 484-495.

Huete, A., Didan, K., Rodriguez, E. P., Gao, X., \& Ferreira, L. G. (2002). Overview Of The Radiometric And Biophysical Performance Of The MODIS Vegetation Indices. Remote Sensing of Environment, 83, 195-213.

Indian and Northern Affairs Canada. (2010). Water Use Inspection Report Form; CIDM\# 429138. Municipality of Pond Inlet .

Jacques, J. M., \& Sauchyn, D. (2009). Increasing Winter Baseflow And Mean Annual Streamflow From Possible Permafrost Thawing in the Northwest Territories, Canada. Geophysical Research Letters, 36, L01401.

Jia, G. J., \& Epstein, H. E. (2003). Greening Of Arctic Alaska, 1981-2001. Geophysical Research Letters, 30(20).

Jia, G.S., Epstein, H.E., \& Walker, D.A. (2009). Vegetation greening in the Canadian Arctic related to decadal warming. Journal of Environmental. Monitoring, 11, 2231-2238.

Jones, J. W. (2015). Efficient Wetland Surface Water Detection and Monitoring via Landsat: Comparison with in situ Data from the Everglades Depth Estimation Network. Remote Sensing, 7(9), 1250312538 .

Laidler, G. J., Treitz, P. M., \& Atkinson, D. A. (2008). Remote Sensing of Arctic Vegetation: Relations between the NDVI, Spatial Resolution and Vegetation Cover on Boothia Peninsula, Nunavut. Arctic, 61(1), 1-13.

Li, P., Jiang, L., \& Feng, Z. (2014). Cross-Comparison of Vegetation Indices Derived from Landsat-7 Enhanced Thematic Mapper Plus (ETM+) and Landsat-8 Operational Land Imager (OLI) Sensors. Journal of Remote sensing, 6, 310-329.

Loseto, L., Lean, D. R., \& Siciliano, S. D. (2004). Snowmelt Sources of Methylmercury to High Arctic Ecosystems. Environmental Science \& Technology, 38(11), 3004-3010.

Lu, D., Mausel, P., Brondizio, E., \& Moran, E. (2004). Change detection techniques. International Journal of Remote sensing, 25(12), 2365-2407.

Lumbierres, M., Méndez, P. F., Bustamante, J., Soriguer, R., \& Santamaria, L. (2017). Modeling Biomass Production in Seasonal Wetlands Using MODIS NDVI Land Surface Phenology. Remote Sensing, 9(392). 
Man, Q. X., Guo, H. D., Liu, G., \& Dong, P. L. (2014). Comparison of different methods for monitoring glacier changes observed by Landsat images. Earth and Environmental Science, 17(1).

Mandanici, E., \& Bitelli, G. (2015). Multi-Image and Multi-Sensor Change Detection for Long-Term Monitoring of Arid Environments with Landsat Series. Journal of Remote sensing, 7, 14019-14038

Meyer, M. F. (1980). Remote sensing of snow and ice. Hydrological Sciences Bulletin, 25(3), 307-330.

Meyer, T., Muir, D.C., Teixeira, C., Wang, X., Young, T., \& Wania, F. (2012). Deposition of Brominated Flame Retardants to the Devon Ice Cap, Nunavut, Canada. Environmental Science and Technology, 46, 826-833.

Natural Resources Canada (NRCan). (2015). Earth Sciences; Pre-processing. Retrieved May 5, 2017, from http://www.nrcan.gc.ca/node/9403

Natural Resources Canada (NRCan). (2016). Geospatial Data Extraction; CanVec_170321_184113; Government of Canada. Retrieved April 10, 2017, from http://geogratis.gc.ca/site/eng/extraction

Neigh, C.S.R., Tucker, C.J., \& Townshend, J.R.G. (2008) North American vegetation dynamics observed with multi-resolution satellite data. Remote Sensing of Environment, 112, 1749-1772.

Nunavut Climate Change Centre (NCCC). (2017). Climate Change In Nunavut. Retrieved 05 29, 2017, from https://climatechangenunavut.ca/en/understanding-climate-change/climate-change-nunavut

Olthof, I., Latifovic, R., \& Pouliot, D. (2015). Northern Land Cover of Canada - Circa 2000. Canada Centre for Remote Sensing - Natural Resources Canada. Retrieved 05 20, 2017, from http://www.nrcan.gc.ca/earth-sciences/land-surface-vegetation/land-cover/north-americanlandcover/9150

Olthof, I., Pouliot, D., Latifovic, R., \& Chen, W. (2008). Recent (1986-2006) Vegetation-Specific NDVI Trends in Northern Canada from Satellite Data. The Arctic Institute of North America, 61(4), 381394.

Overland, J., Hanna, E., Hanssen-Bauer, I., Kim, S.J., Walsh, J.E., Wang, M., Bhatt, U.S., \& Thoman, R.L. (2016). Surface Air Temperature. Arctic Reports: Arctic Report Card: Update for 2016. Retrieved July 5, 2017, from http://arctic.noaa.gov/Report-Card/Report-Card-2016/ArtMID/ 5022/ArticleID/271/Surface-Air-Temperature

Ozesmi, S. L., \& Bauer, M. E. (2002). Satellite remote sensing of wetlands. Wetlands Ecology and Management(10), 381-402.

Paul, F., Huggel, C., \& Kääb, A. (2004). Combining satellite multispectral image data and a digital elevation model for mapping debris-covered glaciers. Remote Sensing of Environment, 89(4), 510-518.

PCI Geomatics. (2016). Geomatica Help. Richmond Hill, Ontario, Canada.

Perreault, N., Lévesque, E., Fortier, D., Gratton, D., \& Lamarque, L. J. (2017). Remote sensing evaluation of High Arctic wetland depletion following permafrost disturbance by thermo-erosion gullying processes. Arctic Science. 
Pettorelli, N., Vik, A. O., Mysterud, A., Gillard, J., Tucker, C. J., \& Stenseth, N. C. (2005). Using The Satellite-Derived NDVI To Assess Ecological Responses To Environmental Change. Trends in Ecology \& Evolution, 20(9), 503-510.

Piwowar, J. M., \& LeDrew, E.F. (1995). Hypertemporal analysis of remotely sensed sea-ice data for climate change studies. Progress in Physical Geography, 19(2), 216-242.

Rabatel, A., Dedieu, J., \& Vincent, C. (2005). Using remote-sensing data to determine equilibrium-line altitude and mass-balance time series: validation on three French glaciers, 1994-2002. Journal of Glaciology, 51(175), 539-546.

Ramsay, G. (2015). Spatial and Temporal Modeling of Biophysical Variables Within a High Arctic Wetland. Toronto: A thesis presented to Ryerson University.

Raynolds, M. K., \& Walker, D. A. (2016). Increased wetness confounds Landsat-derived NDVI trends in the central Alaska North Slope region, 1985-2011. Environmental Research Letters, 11(8).

Roy, D. P., Kovalskyy, V., Zhang, H. K., Vermote, E. F., Yan, L., Kumar, S. S., \& Egorov, A. (2016). Characterization of Landsat-7 to Landsat-8 reflective wavelength and normalized difference vegetation index continuity. Remote Sensing of Environment, 185, 57-70.

Screen, J. A., \& Simmonds, I. (2012). Declining summer snowfall in the Arctic: Causes, impacts and feedbacks. Climate Dynamics, 38(11-12), 2243-2256.

Selkowitz, D. J., \& Forster, R. R. (2015). An automated approach for mapping persistent ice and snow cover over high latitude regions. Remote Sensing, 8(1), 16.

Sharp, M., Burgess, D. O., Cogley, J. G., Ecclestone, M., Labine, C., \& Wolken, G. J. (2011). Extreme melt on Canada's Arctic ice caps in the 21st century. Geophysical Research Letters, 38, L11501.

Silapaswan, C. S., Verbyla, D. L., \& McGuire, A. D. (2001). Land Cover Change on the Seward Peninsula: The Use of Remote Sensing to Evaluate the Potential Influences of Climate Warming on Historical Vegetation Dynamics. Canadian Journal of Remote Sensing, 27(5), 542-554.

Song, C., Woodcock, C. E., Seto, K. C., Lenney, M. P., \& Macomber, S. A. (2001). Classification and Change Detection Using Landsat TM Data: When and How to Correct Atmospheric Effects. Remote Sensing of the Environment, 75(2), 230-244.

Stow, D. A., Hope, A., McGuire, D., Verbyla, D., Gamon, J., Huemmrich, F., \& Tape, K. (2004). Remote sensing of vegetation and land-cover change in Arctic Tundra Ecosystems. Remote Sensing of Environment, 89(3), 281-308.

Tan, K. C., Lim, H. S., MatJafri, M. Z., \& Abdullah, K. (2012). A comparison of radiometric correction techniques in the evaluation of the relationship between LST and NDVI in Landsat imagery. Environmental Monitoring and Assessment, 184(6), 3813-3829.

Tarnocai, C., \& Zoltai, S. C. (1988). Wetlands of Canada: Wetlands of Arctic Canada (Vol. 2). (N. W. Classification, Ed.) Canada: Polyscience Publications Inc.

Toutoubalina, V., \& Rees, W. G. (1999). Remote sensing of industrial impact on Arctic vegetation around Noril'sk, northern Siberia: preliminary results. International Journal of Remote Sensing, 20(15), 2979-2990. 
U.S. Geological Survey (USGS) Earth Resources Observation and Science Center. (2017, March 28). Earth Explorer. Retrieved April 20, 2017, from https://earthexplorer.usgs.gov/

Van Wychen, W., Davis, J., Burgess, D. O., Copland, L., Gray, L., Sharp, M., \& Mortimer, C. (2016). Characterizing interannual variability of glacier dynamics and dynamic discharge (1999-2015) for the ice masses of Ellesmere and Axel Heiberg Islands, Nunavut, Canada. Journal of Geophysical Research, 121, 39-63.

Vincent, W. F., Callaghan, T. V., Dahl-Jensen, D., Johansson, M., Kovacs, K. M., Michel, C., \& Sharp, M. (2011). Ecological Implications of Changes in the Arctic Cryosphere. Ambio, 40(1), 87-99.

Walker, D. A., Raynolds, M. K., Daniels, F.J., Einarsson, E., Elvebakk, A., Gould, W. A., \& Yurtsev, B. A. (2005). The Circumpolar Arctic vegetation map. Journal of Vegetation Science, 267-282. Retrieved from http://www.geobotany.org/library/pubs/WalkerDA2005_jvs_16_267.pdf

Way, R. G. (2014). Multidecadal Recession of Grinnell and Terra Nivea Ice Caps, Baffin Island, Canada. The Arctic Institute of North America, 68(1), 45-53.

Woo, M., \& Young, K. L. (2006). High Arctic wetlands: Their occurrence, hydrological characteristics and sustainability. Journal of Hydrology, 320(3-4), 432-450.

Zhou, L., Tucker, C.J., Kaufmann, R.K, Slayback, D., Shabanov, N.V., \& Myneni, R.B. (2001) Variations in northern vegetation activity inferred from satellite data of vegetation index during 1981 to 1999. J. Geophys. Res., 106(20), 69-83. 